\title{
Comunidade arbórea de um continuum entre floresta paludosa e de encosta em Coqueiral, Minas Gerais, Brasil
}

\author{
CINTHIA TAMARA V. ROCHA ${ }^{1,5}$, DOUGLAS ANTÔNIO DE CARVALHO², \\ MARCO AURÉLIO L. FONTES ${ }^{3}$, ARY TEIXEIRA DE OLIVEIRA FILHO', \\ EDUARDO VAN DEN BERG ${ }^{2}$ e JOÃO JOSÉ G.S. MELO MARQUES ${ }^{4}$
}

(recebido: 28 de agosto de 2003; aceito: 25 de novembro de 2004)

\begin{abstract}
Community of trees of a continuum from swampy to upland forest in Coqueiral, SE Brazil). The purpose of the present contribution was to describe the community of trees of a continuum extending from swampy to upland forest in Coqueiral, SE Brazil, assessing the correlations between the variations of community structure and those of the environment. Sampling was carried out in 25 plots of $20 \times 20 \mathrm{~m}$ laid on the forest fragment to survey trees with a minimum circumference of $15.5 \mathrm{~cm}$ (registering their circumference, height and species) as well as topographic and soil variables. Species-environment correlations were analyzed using canonical correspondence analysis (CCA) and Spearman's test. The swampy and upland habitats differed substantially in both community structure and floristic composition. The general floristic profile was similar to that of other riparian forests of the Mid and Upper Rio Grande region, whilst the swampy portion of the forest differed from what is commonly found in SE Brazil. The species distribution was correlated mainly to soil drainage and proximity to the lake. The high soil diversity and the strong soil moisture gradient found over a small area resulted in different habitats and a diverse community of trees and shrubs that combined phyto-physiognomies of semideciduous and swampy forests, along with cerrado patches.
\end{abstract}

Key words - ecotone zone, environment-vegetation relationship, riverine forest, swampy forest, tropical semideciduous forest

RESUMO - (Comunidade arbórea de um continuum entre floresta paludosa e de encosta em Coqueiral, Minas Gerais, Brasil). Neste trabalho objetivou-se descrever a comunidade arbórea de um continuum entre floresta paludosa e de encosta em Coqueiral, Minas Gerais, verificando correlações entre variações na estrutura da comunidade e ambiente. Distribuíram-se 25 parcelas de $20 \times 20 \mathrm{~m}$ pelo fragmento florestal, onde se levantaram altura, circunferência (mínima de 15,5 $\mathrm{cm}$ ) e identidade botânica de todos indivíduos e coletaram-se variáveis topográficas e edáficas. As correlações espécie-ambiente foram analisadas por análise de correspondência canônica (CCA) e teste de Spearman. Os hábitats paludoso e de encosta diferiram em estrutura e espécies. Encontrou-se perfil florístico comum às matas ciliares do Alto e Médio Rio Grande, enquanto a porção paludosa diferenciou-se do encontrado no sudeste. A distribuição das espécies correlacionou-se principalmente com a drenagem do solo e proximidade da lagoa. A grande diversidade edáfica e o forte gradiente de umidade sobre uma área pequena resultaram em diferentes hábitats e em uma comunidade arbórea diversa, combinando fitofisionomias de florestas semidecídua e paludosa, além de resquícios de cerrado.

Palavras-chave - correlação espécie-ambiente, ecótono, floresta estacional semidecídua, floresta paludosa, floresta ripária

\section{Introdução}

As florestas ripárias estão entre os ecossistemas mais ameaçados do Brasil. Estas florestas funcionam como reguladores de processos erosivos, estabilizam

1. Universidade Federal de Minas Gerais, Instituto de Ciências Biológicas, Departamento de Botânica, Av. Antônio Carlos, 6627, Pampulha, Caixa Postal 486, 31270-910 Belo Horizonte, MG, Brasil.

2. Universidade Federal de Lavras, Departamento de Biologia, 37200-000 Lavras, MG, Brasil.

3. Universidade Federal de Lavras, Departamento de Ciências Florestais, 37200-000, Lavras, MG, Brasil.

4. Universidade Federal de Lavras, Departamento de Ciências do Solo, 37200-000 Lavras, MG, Brasil.

5. Autor para correspondência: cinthiamalf@hotmail.com. margens, promovem ciclagem de nutrientes, freiam a carreação de sedimentos para o meio aquático, facilitam a interação solo-água-fauna e promovem a estabilidade térmica dos corpos d'água, entre outras funções (Lima 1989, Pedralli \& Teixeira 1997). Apesar de sua importância, as matas ripárias aproximam-se da erradicação em várias partes do país (Gibbs et al. 1980). No sul de Minas Gerais, a formação já se encontra reduzida a pequenos fragmentos (Oliveira Filho et al. 1994b). As matas ripárias são divididas em permanentemente inundada ou de brejo, inundada anualmente ou de várzea e mata seca (Rodrigues \& Shepherd 1993). As matas de brejo ou florestas paludosas têm distribuição naturalmente fragmentada (Torres et al. 1994, Ivanauskas et al. 1997, Toniato et al. 1998, Paschoal \& Cavassan 1999), pois se 
encontram restritas aos solos hidromórficos, apresentando espécies capazes de germinar e crescer em condições de saturação hídrica e conseqüente falta de oxigênio (Joly 1986). Estas características edáficas exercem forte pressão seletiva, promovendo a instalação de poucas espécies adaptadas ao ambiente. Os fatores que definem a ocorrência de floresta paludosa (fisionomia florestal) ou de campo úmido (fisionomia herbácea) ainda são pouco conhecidos (Rodrigues \& Nave 2000). São também florestas muito pouco estudadas no Brasil (Toniato et al. 1998). As pesquisas limitam-se, até o momento, ao Estado de São Paulo, onde as florestas paludosas encontram-se muito degradadas (Torres et al. 1994). Tal situação deve-se repetir em grande parte do país, associada à perda das florestas ripárias como um todo. Em Minas Gerais, nenhuma floresta paludosa foi estudada, sendo esta pesquisa pioneira.

O objetivo deste trabalho foi descrever a comunidade arbórea de um fragmento florestal constituído por um continuum entre floresta semidecidual montana e floresta paludosa, no Município de Coqueiral, Sul de Minas Gerais, verificando possíveis correlações entre as variações em sua estrutura e variáveis ambientais.

\section{Material e métodos}

A floresta ocupa cerca de 10 ha e localiza-se na Fazenda Lagoa, Município de Coqueiral, MG $\left(21^{\circ} 09^{\prime} 19^{\prime}\right.$ ' S e $45^{\circ} 28^{\prime} 17^{\prime \prime} \mathrm{W} ; 810$ a $840 \mathrm{~m}$ de altitude), às margens de uma lagoa natural cujas águas fluem para o Rio Marimbondo, afluente da Represa de Furnas. O clima, segundo estação climatológica mais próxima, em Lavras, é do tipo Cwb de Köppen ou mesotérmico com verões brandos e suaves e estiagem de inverno. A média anual de precipitação é de $1.493 \mathrm{~mm}$ e de temperatura $19,3{ }^{\circ} \mathrm{C}$ (Vilela \& Ramalho 1979). A área insere-se no domínio da Mata Atlântica (sensu Oliveira Filho \& Fontes 2000) e constitui-se de um continuum entre floresta estacional semidecidual montana (Veloso et al. 1991) e floresta estacional semidecidual ribeirinha com influência fluvial permanente (Rodrigues 2000), designados doravante e respectivamente como hábitats de encosta e paludoso. O fragmento é circundado, além da lagoa ao sul, por pastagens a leste e oeste e uma estrada ao norte. Relatos dos proprietários e de antigos conhecedores da área falam de coletas seletivas de espécies madeiráveis há cerca de 40 anos, da não ocorrência de cortes rasos e da ausência de explotação presente. Coerentemente, não se encontram na área sinais de retiradas recentes de madeira, apesar de existir grande número de árvores de porte e forma comercialmente atraentes. Além disso, a floresta é parcialmente cercada, não havendo sinais de entrada de gado, porém é usada para caça e apresenta vestígios de incêndios em sua borda noroeste.

No levantamento estrutural alocaram-se 25 parcelas de $20 \times 20 \mathrm{~m}$, totalizando 1 ha, distribuídas sistematicamente em 5 transeções dispostas da margem do lago até a borda da mata. A distância entre parcelas e transeções foi de $20 \mathrm{~m}$. Uma sexta transeção foi alocada nas porções mais baixas do terreno, onde ocorre o afloramento permanente do lençol freático. As distâncias entre parcelas nesse local foram menores e variáveis, objetivando aumentar a amostragem de espécies típicas desse ambiente (figura 1). Nessas parcelas, todos indivíduos com circunferência à altura do peito (CAP, tomada a $1,30 \mathrm{~m}$ acima do nível do solo) $\mathrm{t} 15,7 \mathrm{~cm}$ foram marcados, medidos em seus valores de CAP e altura total e identificados. A identificação baseou-se em coletas botânicas, seguidas de herborização e comparação com espécimes no Herbário ESAL, da Universidade Federal de Lavras (UFLA) e por consultas à literatura e a especialistas, utilizando-se as famílias reconhecidas pelo sistema do Angiosperm Phylogeny Group (APG II 2003). Para melhor caracterização florística, a área foi percorrida levantando-se espécies não ocorrentes nas parcelas.

Para levantamento de variáveis ambientais, foi coletada com uso de trado, em cada parcela, uma amostra composta do solo superficial $(0-20 \mathrm{~cm})$ com cerca de $500 \mathrm{~g}$, constituída de três subamostras coletadas dentro da parcela. As amostras foram armazenadas em sacos plásticos, identificadas e enviadas para o Laboratório de Análise de Solos da UFLA, sendo submetidas à análise química e textural, de acordo com os métodos adotados pela Embrapa (1997), obtendo-se as variáveis: $\mathrm{pH}, \mathrm{P}, \mathrm{K}, \mathrm{Ca}^{2+}, \mathrm{Mg}^{2+}, \mathrm{Al}^{3+}$, índice de saturação de bases (V), matéria orgânica (MO) e teores de areia, silte e argila. Os solos foram classificados em campo segundo o Sistema Brasileiro de Classificação dos Solos (Embrapa 1999). Realizou-se levantamento topográfico com uso de clinômetro e trena, gerando uma grade de superfície (figura 1A) e obtendo-se as variáveis cota (média dos vértices de cada parcela) e desnível (diferença entre cotas máxima e mínima), seguindo método proposto por Oliveira Filho et al. (1994a) e van den Berg \& Oliveira Filho (1999). Considerando-se a proximidade da margem da lagoa uma variável que engloba umidade do solo, disponibilidade de luz e susceptibilidade a inundações, calculou-se o valor de margem conforme método de Oliveira Filho et al. (1997), adaptado por Souza et al. (2003). Este consiste do comprimento linear da margem inserida em um círculo imaginário com raio de $100 \mathrm{~m}$ e origem no centro da parcela, medido entre os pontos de interseção encontrados. Um valor correspondente à borda da mata foi calculado para cada parcela pelo mesmo procedimento. Por fim, cada parcela foi classificada em sua drenagem, segundo método proposto pela Embrapa (1999), para localização do hábitat palusoso.

$\mathrm{Na}$ análise fitossociológica foram utilizados os parâmetros densidade, frequiência e dominância (em área basal) absolutos e valor de importância (VI) (MuellerDombois \& Ellenberg 1974) e os índices de diversidade de 

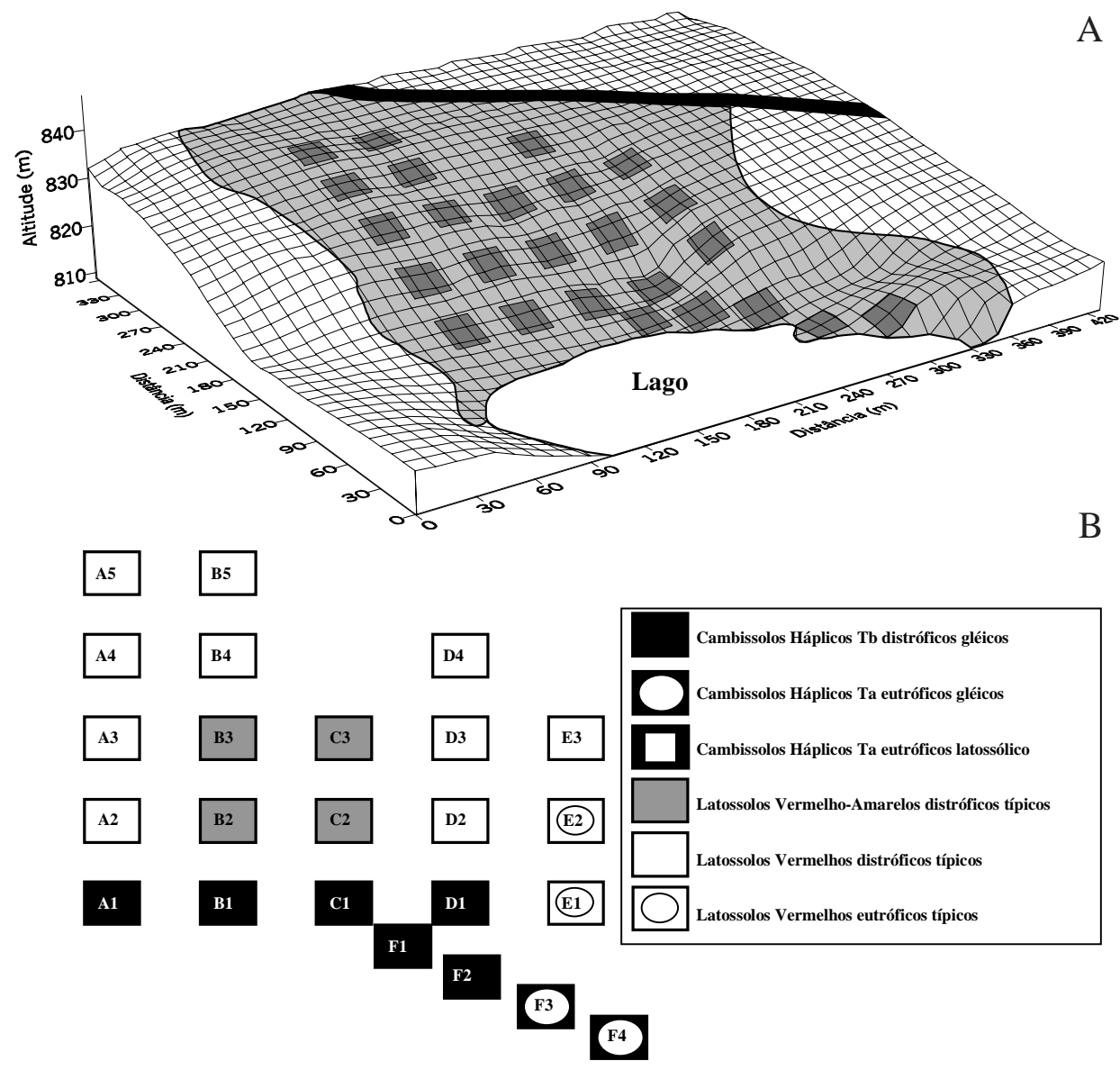

Figura 1. Grade de relevo com parcelas de 20×20 m em floresta ripária em Coqueiral, MG (A) (o espaçamento entre linhas é igual a 10 m) e identificação das parcelas e classificação dos solos (B) (a área paludosa corresponde às parcelas A1, B1, C1, D1, F1, F2, F3 e F4).

Figure 1. Surface gridline showing the sample plots with $20 \times 20 \mathrm{~m}$ of dimensions used to survey the area of riparian forest in Coqueiral, SE Brazil (A) (lines are spaced at $10 \mathrm{~m}$ intervals), and plots identification and soil classification (B) (the swampy area corresponds to plots A1, B1, C1, D1, F1, F2, F3 and F4).

Shannon (em nats.indivíduo ${ }^{-1}$ ) e de equabilidade de Pielou (Brower \& Zar 1984), calculados no programa Fitopac 1 (Shepherd 1994). As variáveis topográficas, edáficas e estruturais (densidade, área basal e diâmetro e altura médios) por parcela foram comparadas entre os hábitats paludoso e encosta por análises de variância (Zar 1996). Diâmetros e alturas também foram avaliados pelas suas distribuições de frequência nos dois hábitats.

Para análise das correlações entre os gradientes ambientais e vegetacionais foi empregada a análise de correspondência canônica ou CCA (Ter Braak 1987), sendo esta ordenação indicada para visualização de relações estreitas entre variáveis ambientais e abundância das espécies (Kent \& Coker 1992). Utilizou-se uma matriz de abundância de espécies, eliminando-se aquelas com número de indivíduos inferior a dez, e uma matriz de variáveis ambientais. Após uma primeira análise pela CCA, retiraram-se três parcelas $(\mathrm{A} 3, \mathrm{~A} 4 \mathrm{e}$ A5) que formavam um grupo muito coeso em similaridade que impedia a visualização dos padrões das demais parcelas. Em um segundo momento, trabalhou-se com matriz de 29 espécies e respectivas abundâncias em 22 parcelas. Retiraram-se todas as variáveis ambientais com correlação com os eixos da ordenação inferior a 0,4 ou com alta redundância (conforme Oliveira Filho et al. 1994a), ficando a matriz ambiental com nove variáveis: $\mathrm{pH}, \mathrm{Al}^{3+}, \mathrm{V}, \mathrm{MO}$, silte, argila, cota, margem e drenagem. Calcularam-se, ainda, coeficientes de correlação de Spearman (Zar 1996) entre a abundância das 29 espécies e o valor das variáveis ambientais nas 22 parcelas.

\section{Resultados}

Foram encontradas 242 espécies (161 nas parcelas), distribuídas em 144 gêneros e 58 famílias (tabela 1). Os gêneros com maior número de espécies foram Miconia (10), Ocotea, Eugenia (8 cada), 
Tabela 1. Espécies arbóreas levantadas em floresta ripária em Coqueiral, MG, em ordem alfabética de famílias botânicas e seguidas dos números de registro no Herbário ESAL. * = espécies registradas fora das parcelas.

Table 1. Tree species surveyed in an area of riparian forest in Coqueiral, SE Brazil, ranked in alphabetical order of botanical families and followed by their registration number in the ESAL Herbarium. $*=$ species registered outside sample plots.

\begin{tabular}{|c|c|c|c|}
\hline Família/Espécie & ESAL & Família/Espécie & ESAL \\
\hline ANACARDIACEAE & & CELASTRACEAE & \\
\hline Lithraea molleoides (Vell.) Engler & *12332 & Cheiloclinium cognatum (Miers) A.C.Smith & *12378 \\
\hline Tapirira guianensis Aublet & 12329 & Maytenus robusta Reissek & $* 14848$ \\
\hline Tapirira obtusa (Benth.) Mitchell & 12330 & Salacia elliptica (Mart.) G.Don & 12842 \\
\hline ANNONACEAE & & CELTIDACEAE & \\
\hline Annona cacans Warm. & 16367 & Celtis iguanaea (Jacquin) Sargent & $* 15726$ \\
\hline Duguetia lanceolata A.St.-Hil. & 14936 & CHRYSOBALANACEAE & \\
\hline Guatteria nigrescens Mart. & 12648 & Licania octandra (Hoffmgg.) Kuntze & 17570 \\
\hline Rollinia laurifolia Schltdl. & 16371 & CLUSIACEAE & \\
\hline Rollinia sericea (R.E.Fries) R.E.Fries & 16372 & Calophyllum brasiliense Cambess. & 12814 \\
\hline Xylopia aromatica (Lam.) Mart. & 15607 & Clusia criuva Cambess. & 17568 \\
\hline Xylopia brasiliensis Sprengel & 16374 & Vismia brasiliensis Choisy & 17569 \\
\hline Xylopia emarginata Mart. & $* 12647$ & COMBRETACEAE & \\
\hline APOCYNACEAE & & Terminalia phaeocarpa Eichler & $* 14555$ \\
\hline Aspidosperma cylindrocarpon Müll.Arg. & $* 17561$ & CONNARACEAE & \\
\hline Aspidosperma polyneuron Müll.Arg. & 16377 & Connarus regnellii G.Schellenb. & 16768 \\
\hline Malouetia arborea (Vell.) Miers & 14865 & CUNONIACEAE & \\
\hline AQUIFOLIACEAE & & Lamanonia ternata Vell. & $* 16428$ \\
\hline Ilex cerasifolia Reissek & 16380 & CYATHEACEAE & \\
\hline Ilex cognata Reissek & 17562 & Cyathea delgadii Sternb. & *13395 \\
\hline ARALIACEAE & & Cyathea phalerata Mart. & 17571 \\
\hline Aralia warmingiana (E.Marchal) Harms & 17563 & ERYTHROXYLACEAE & \\
\hline Dendropanax cuneatus (DC.) Decne \& Planch. & 16382 & Erythroxylum deciduum A.St.-Hil. & $* 17094$ \\
\hline Schefflera calva (Cham.) D.Frodin & 17564 & Erythroxylum pelleterianum A.St.-Hil. & $* 17560$ \\
\hline Schefflera vinosa (Cham. \& Schtdl.) D.Frodin & $* 16679$ & EUPHORBIACEAE & \\
\hline $\begin{array}{l}\text { ARECACEAE } \\
\text { Geonoma schottiang Mart }\end{array}$ & & Actinostemon klotzschii (Didrichs) Pax & 17572 \\
\hline $\begin{array}{l}\text { Geonoma schottiana Mart. } \\
\text { Syagrus romanzoffiana (Cham.) Glassman }\end{array}$ & $* 16385$ & Alchornea glandulosa Poepp. \& Endl. & 16783 \\
\hline $\begin{array}{l}\text { Syagrus romanzoffiana (Cham.) Glassman } \\
\text { ASTERACEAE }\end{array}$ & 10903 & Croton floribundus Sprengel & 12812 \\
\hline $\begin{array}{l}\text { ASIERACEAE } \\
\text { Eupatorium inulaefolium Kunth }\end{array}$ & & Croton piptocalyx Müll.Arg. & $* 17380$ \\
\hline Piptocarpha macropoda Baker & $* 16744$ & Croton urucurana Baillon & $* 16440$ \\
\hline Vernonanthura diffusa (Less.) H.Robinson & 17565 & Hyeronima ferruginea Müll.Arg. & $* 16441$ \\
\hline BIGNONIACEAE & & Maprounea guianensis Aublet & 17573 \\
\hline Cybistax antisyphillitica Mart. & 13245 & Sapium glandulosum (L.) Morong & $* 16443$ \\
\hline Jacaranda macrantha Cham. & $* 16390$ & Savia dictyocarpa (Müll.Arg.) Müll.Arg. & 14556 \\
\hline Tabebuia ochracea (Cham.) Rizz. & $* 16391$ & Sebastiania brasiliensis Sprengel & *12186 \\
\hline Tabebuia serratifolia (Vahl) Nichols & 16392 & Sebastiania commersoniana (Baillon) Smith \& Downs & is 12815 \\
\hline Tabebuia umbellata (Sond.) Sandw. & 17566 & FABACEAECAESALPINIOIDEAE & \\
\hline Zeyheria tuberculosa (Vell.) Bureau & *14616 & Bauhinia longifolia (Bongard) Steudel & 17577 \\
\hline BORAGINACEAE & & Copaifera langsdorffii Desf. & 12861 \\
\hline Cordia sellowiana Cham. & *16396 & Hymenaea courbaril $\mathrm{L}$. & 16493 \\
\hline Cordia trichotoma (Vell.) Arrab. & *16397 & Sclerolobium rugosum Mart. & *16494 \\
\hline BURSERACEAE & & Senna macranthera (Vell.) Irwin \& Barneby & 11558 \\
\hline Protium heptaphyllum (Aublet) Marchand & 17567 & Senna multijuga (L.C.Rich.) Irwin \& Barneby & $* 16497$ \\
\hline Protium spruceanum (Benth.) Engler & 16399 & FABACEAEFABOIDEAE & \\
\hline Protium widgrenii Engler & 12607 & Andira fraxinifolia Benth. & 17578 \\
\hline CECROPIACEAE & & Bowdichia virgilioides Kunth & $* 16510$ \\
\hline Cecropia glaziovii Snethl. & 16403 & Dalbergia villosa (Benth.) Benth. & 17579 \\
\hline
\end{tabular}


continuação

\begin{tabular}{|c|c|c|c|}
\hline Família/Espécie & ESAL & Família/Espécie & ESAL \\
\hline Erythrina falcata Benth. & $* 16514$ & Ocotea corymbosa (Meisner) Mez & 12854 \\
\hline Lonchocarpus cultratus (Vell.) Tozzi \& Lima & $* 16515$ & Ocotea diospyrifolia (Meisner) Mez & 17596 \\
\hline Machaerium brasiliense Vogel & 17580 & Ocotea elegans $\mathrm{Mez}$ & 17597 \\
\hline Machaerium hirtum (Vell.) Stellfeld & 16847 & Ocotea glaziovii $\mathrm{Mez}$ & 17598 \\
\hline Machaerium lanceolatum (Vell.) Macbr. & 17581 & Ocotea indecora (Schott) Mez & 17599 \\
\hline Machaerium nictitans (Vell.) Benth. & 5919 & Ocotea odorifera (Vell.) Rohwer & 12851 \\
\hline Machaerium villosum Vogel & 11532 & Ocotea pulchella Mart. & 12849 \\
\hline Myroxylon peruiferum L.f. & 17582 & Persea pyrifolia Nees \& Mart. & 12850 \\
\hline Ormosia arborea (Vell.) Harms & 17583 & LECYTHIDACEAE & \\
\hline Platycyamus regnellii Benth. & 16524 & Cariniana estrellensis (Raddi) Kuntze & 17600 \\
\hline Platypodium elegans Vogel & 16523 & Cariniana legalis (Mart.) Kuntze & 17013 \\
\hline Pterodon emarginatus Vogel & $* 16889$ & LOGANIACEAE & \\
\hline Sweetia fruticosa Sprengel & 14673 & Strychnos brasiliensis (Sprengel) Mart. & $* 16838$ \\
\hline FABACEAE MIMOSOIDEAE & & LYTHRACEAE & \\
\hline Acacia glomerosa Benth. & 17584 & Lafoensia pacari A.St.-Hil. & 13103 \\
\hline Acacia polyphylla DC. & 17585 & MAGNOLIACEAE & \\
\hline Albizia polycephala (Benth.) Killip & 17586 & Talauma ovata A.St.-Hil. & 16842 \\
\hline Inga marginata Willd. & 17587 & MALPIGHIACEAE & \\
\hline Inga striata Benth. & 12867 & Heteropterys byrsonimifolia A.Juss. & $* 08663$ \\
\hline Leucochloron incuriale (Vell.) Barn. \& Grimes & $* 16505$ & MALVACEAE & \\
\hline Piptadenia gonoacantha (Mart.) Macbr. & $* 16507$ & Eriotheca candolleana (K.Schum.) A.Robyns & *13091 \\
\hline Pseudopiptadenia leptostachya (Benth.) Rausch & h. 17588 & Luehea candicans Mart. & $* 16853$ \\
\hline Zygia latifolia (L.) Fawc. \& Rendle & 17589 & Luehea divaricata Mart. \& Zucc. & 16616 \\
\hline FLACOURTIACEAE & & Luehea grandiflora Mart. \& Zucc. & $* 09462$ \\
\hline Casearia aculeata Jacquin & 17574 & MELASTOMATACEAE & \\
\hline Casearia decandra Jacquin & 9614 & Leandra melastomoides Raddi & $* 09901$ \\
\hline Casearia lasiophylla Eichler & 9729 & Leandra scabra DC. & 9900 \\
\hline Casearia obliqua Sprengel & 12839 & Leandra sericea DC. & *09905 \\
\hline Casearia sylvestris Swartz & 9598 & Miconia albicans Triana & $* 00744$ \\
\hline Casearia ulmifolia Vahl & 17575 & Miconia argyrophylla DC. & 9903 \\
\hline Xylosma ciliatifolium (Clos) Eichler & 12837 & Miconia chamissois Naudin & $* 11637$ \\
\hline Xylosma prockia (Turcz.) Turcz. & 17576 & Miconia cinerascens Miq. & 17601 \\
\hline ICACINACEAE & & Miconia cinnamomifolia (DC.) Naudin & $* 12880$ \\
\hline Citronella paniculata (Mart.) Howard & 17590 & Miconia latecrenata (DC.) Naudin & 17602 \\
\hline LACISTEMACEAE & & Miconia ligustroides (DC.) Naudin & $* 11882$ \\
\hline Lacistema hasslerianum Chodat & 16460 & Miconia pepericarpa $\mathrm{DC}$. & $* 09918$ \\
\hline LAMIACEAE & & Miconia theaezans (Bonpl.) Cogn & *09802 \\
\hline Aegiphila sellowiana Cham. & $* 16944$ & Miconia tristis Sprengel & 17603 \\
\hline Vitex cymosa Bert. & $* 16623$ & MELIACEAE & \\
\hline Vitex megapotamica (Sprengel) Moldenke & 1600 & Cabralea canjerana (Vell.) Mart. & 9604 \\
\hline Vitex polygama Cham. & *12974 & Guarea guidonia $(\mathrm{L}$.) Sleumer & *10113 \\
\hline LAURACEAE & & Guarea kunthiana A.Juss. & $* 16554$ \\
\hline Aniba firmula (Nees \& Mart.) Mez & 17591 & Guarea macrophylla Vahl. & *12233 \\
\hline Cryptocarya aschersoniana $\mathrm{Mez}$ & 16804 & Trichilia catigua A.Juss. & 17604 \\
\hline Endlicheria paniculata (Sprengel) Macbr. & 17592 & Trichilia clausseni C.DC. & 17605 \\
\hline Nectandra cissiflora Nees & 17593 & Trichilia emarginata (Turcz.) C.DC. & 17606 \\
\hline Nectandra grandiflora Nees & 17594 & Trichilia pallida $\mathrm{S} w a r t z$ & 16863 \\
\hline Nectandra lanceolata Nees & 12853 & Trichilia silvatica C.DC. & 17607 \\
\hline Nectandra megapotamica (Sprengel) Mez & 16808 & MONIMIACEAE & \\
\hline Nectandra oppositifolia Nees & 12845 & Mollinedia widgrenii A.DC. & 16864 \\
\hline Ocotea aciphylla (Nees) Mez & 17595 & & \\
\hline
\end{tabular}


continuação

\begin{tabular}{|c|c|c|c|}
\hline Família/Espécie & ESAL & Família/Espécie & ESAL \\
\hline MORACEAE & & Piper arboreum Aublet & 17629 \\
\hline Ficus insipida Willd. & $* 17159$ & Piper cernuит Vell. & 17630 \\
\hline Ficus mexiae Standley & *16868 & Piper gaudichaudianum Kunth & *09726 \\
\hline Ficus pertusa L.f. & 17608 & PROTEACEAE & \\
\hline Ficus tomentella (Miq.) Miq. & 17162 & Roupala brasiliensis Klotzch & 8786 \\
\hline Maclura tinctoria (L.) D.Don. & $* 16869$ & ROSACEAE & \\
\hline Sorocea bonplandii (Baillon) W.Burger & 16870 & Prunus myrtifolia (L.) Urban & $* 16574$ \\
\hline MYRSINACEAE & & RUBIACEAE & \\
\hline Myrsine coriacea (Swartz) R.Br. & 17620 & Alibertia concolor (Cham.) K.Schum. & 16911 \\
\hline Myrsine intermedia (Mez) Pipoly & 17621 & Alseis floribunda Schott & 17631 \\
\hline Myrsine umbellata Mart. & $* 11533$ & Amaioua guianensis Aublet & 12955 \\
\hline Stylogyne ambigua (Mart.) Mez & 17622 & Coutarea hexandra (Jacquin) K.Schum. & 17632 \\
\hline MYRTACEAE & & Genipa americana L. & 17633 \\
\hline Calycorectes acutatus (Miq.) Toledo & $\begin{array}{r}16465 \\
* 12027\end{array}$ & Ixora warmingii Müll.Arg. & 17634 \\
\hline Calyptranthes clusiifolia (Miq.) O.Berg & $\begin{array}{r}* 12927 \\
17609\end{array}$ & Posoqueria latifolia (Rudge) Roem. \& Schult. & $* 13227$ \\
\hline $\begin{array}{l}\text { Calyptranthes luclaa Mart. } \\
\text { Campomanesia guazumifolia (Camb.) O.Berg }\end{array}$ & $* 16877$ & Psychotria carthagenensis Jacquin & *16585 \\
\hline Campomanesia velutina (Camb.) O.Berg & 17610 & Psychotria deflexa DC. & $* 16919$ \\
\hline Eugenia cerasiflora Miq. & 17611 & Psychotria hastisepala Müll.Arg. & *16587 \\
\hline Eugenia excelsa O.Berg & 17612 & Psychotria vellosiana Benth & 9860 \\
\hline Eugenia florida DC. & 12925 & RUTACEAE & \\
\hline Eugenia handroana D.Legrand & 17613 & Esenbeckia leiocarpa Engler & 17204 \\
\hline Eugenia involucrata DC. & 17614 & Galipea jasminiflora (A.St.-Hil.) Engler & 16922 \\
\hline Eugenia pluriflora DC. & $* 12934$ & Metrodorea stipularis Mart. & 16923 \\
\hline Eugenia sp. (nova) & $* 01200$ & Zanthoxylum caribaeum Lam. & $* 16595$ \\
\hline Eugenia stictosepala Kiaersk. & $* 15710$ & Zanthoxylum fagara (L.) Sargent & $* 16596$ \\
\hline Gomidesia affinis (Cambess.) D.Legrand & 12931 & Zanthoxylum petiolare A.St.-Hil. \& Tul. & 17635 \\
\hline Gomidesia anacardiifolia (Gardner) O.Berg & 17615 & Zanthoxylum rhoifolium Lam. & 16598 \\
\hline Marlierea racemosa (Vell.) Kiaersk. & 17616 & SAPINDACEAE & \\
\hline Myrcia breviramis (O.Berg) D.Legrand & *16477 & Cupania vernalis Cambess. & 16925 \\
\hline Myrcia fallax (Rich.) DC. & 9624 & Matayba elaeagnoides Radlk. & 13330 \\
\hline Myrcia laruotteana Cambess. & $* 16889$ & Matayba guianensis Aublet & $* 16601$ \\
\hline Myrcia multiflora (Lam.) DC. & $* 16890$ & Matayba juglandifolia (Cambess.) Radlk. & 12559 \\
\hline Myrcia rostrata DC. & *16891 & SAPOTACEAE & \\
\hline Myrcia tomentosa (Aublet) DC. & $* 16892$ & Chrysophyllum gonocarpum (Mart. \& Eichl.) Engl. & 17636 \\
\hline Myrciaria floribunda (West) O.Berg & 9862 & Pouteria glomerata (Miq.) Radlk & 17637 \\
\hline Plinia grandifolia (Mattos) Sobral & 17617 & SIPARUNACEAE & \\
\hline Psidium cattleyanum Sabine & 12503 & Siparuna cujabana (Mart.) A.DC. & $* 01316$ \\
\hline Psidium robustum $\mathrm{O}$.Berg & 17618 & Siparuna guianensis Aublet & 9687 \\
\hline Psidium rufum Mart. & 17619 & SOLANACEAE & \\
\hline Siphoneugena densiflora O.Berg & 17624 & Cestrum laevigatum Schltdl. & $* 16931$ \\
\hline Siphoneugena kuhlmannii Mattos & 17625 & Solanum cernuит Vell. & 17638 \\
\hline $\begin{array}{l}\text { NYCTAGINACEAE } \\
\text { Guapira graciliflora (Schmidt) Lundell }\end{array}$ & $* 03105$ & Solanum pseudoquina A.St.-Hil. & $* 16608$ \\
\hline OCHNACEAE & & $\begin{array}{l}\text { STYRACACEAE } \\
\text { Styrax camporus } \text { Pohl }\end{array}$ & \\
\hline Ouratea semiserrata (Mart. \& Nees) Engler & 17623 & $\begin{array}{l}\text { Styrax camporus Pohl } \\
\text { THYMELAEACEAE }\end{array}$ & 17639 \\
\hline $\begin{array}{l}\text { OLACACEAE } \\
\text { Heisteria silvianii Schwacke }\end{array}$ & 17626 & Daphnopsis fasciculata (Meisner) Nevling & *09938 \\
\hline PHYTOLACCACEAE & 17020 & VERBENACEAE & \\
\hline Seguieria langsdorffii Moq. & 17627 & Cytharexylum myrianthum Cham. & 17640 \\
\hline PICRAMNIACEAE & & VOCHYSIACEAE & \\
\hline Picramnia sellowii Planchon & *14576 & Qualea multiflora Mart. & 6177 \\
\hline PIPERACEAE & & Vochysia magnifica Warm. & 16306 \\
\hline Piper amalago $\mathrm{L}$. & 17628 & Vochysia tucanorum Mart. & 11564 \\
\hline
\end{tabular}


Casearia, Myrcia (6 cada), Machaerium, Nectandra, Trichilia (5 cada), contribuindo com $22 \%$ das espécies. As famílias mais ricas foram Fabaceae (30 espécies), Myrtaceae (29), Lauraceae (17), Melastomataceae (13), Rubiaceae (11), Euphorbiaceae e Meliaceae (9 cada), somando $49 \%$ da flora. Vinte e duas famílias (38\%) foram representadas por apenas uma espécie.
No hábitat paludoso foram amostrados 585 indivíduos, distribuídos em 99 espécies de 35 famílias (tabela 2). As famílias mais ricas foram Fabaceae (13 espécies), Lauraceae e Myrtaceae (12 cada), Meliaceae (6), Annonaceae (5), Salicaceae e Rubiaceae (4), representando $57 \%$ da flora da mata paludosa, na qual $51 \%$ das famílias apresentaram só uma espécie. Os

Tabela 2. Espécies arbóreas amostradas em 8 parcelas de $20 \times 20 \mathrm{~m}$ em hábitat paludoso de uma floresta ripária em Coqueiral, MG, e parâmetros quantitativos: $\mathrm{N}$ = número de indivíduos, $\mathrm{P}=$ número de parcelas com ocorrência da espécie e DoA = dominância absoluta $\left(\mathrm{m}^{2} \cdot \mathrm{ha}^{-1}\right)$. Espécies ordenadas por DoA decrescente.

Table 2. Tree species surveyed in eight sample plots of $20 \times 20 \mathrm{~m}$ of dimensions in the swampy habitat of an area of riparian forest in Coqueiral, SE Brazil, and their quantitative parameters: $\mathrm{N}=$ number of individuals, $\mathrm{P}=$ number of sample plots with the species, and DoA $=$ absolute dominance $\left(\mathrm{m}^{2} \cdot \mathrm{ha}^{-1}\right)$. Species ranked by decreasing DoA.

\begin{tabular}{|c|c|c|c|c|c|c|c|}
\hline Espécie & $\mathrm{N}$ & $\mathrm{P}$ & DoA & Espécie & $\mathrm{N}$ & $\mathrm{P}$ & DoA \\
\hline Talauma ovata & 146 & 8 & 11,689 & Casearia sylvestris & 5 & 3 & 0,123 \\
\hline Copaifera langsdorffii & 13 & 5 & 3,068 & Piper cernuит & 8 & 2 & 0,121 \\
\hline Tapirira obtusa & 29 & 8 & 2,940 & Zanthoxylum petiolare & 2 & 1 & 0,119 \\
\hline Calophyllum brasiliense & 45 & 6 & 2,343 & Miconia argyrophylla & 1 & 1 & 0,117 \\
\hline Dendropanax cuneatus & 31 & 7 & 2,323 & Trichilia pallida & 5 & 3 & 0,115 \\
\hline Tabebuia serratifolia & 4 & 3 & 1,176 & Chrysophyllum gonocarpum & 3 & 2 & 0,109 \\
\hline Cryptocarya aschersoniana & 5 & 3 & 0,876 & Trichilia clausseni & 4 & 2 & 0,103 \\
\hline Metrodorea stipularis & 13 & 4 & 0,819 & Protium spruceanum & 2 & 2 & 0,101 \\
\hline Luehea divaricata & 5 & 3 & 0,621 & Inga marginata & 5 & 2 & 0,094 \\
\hline Tapirira guianensis & 11 & 5 & 0,570 & Ocotea diospyrifolia & 2 & 2 & 0,088 \\
\hline Aspidosperma polyneuron & 3 & 3 & 0,562 & Ixora warmingii & 2 & 2 & 0,088 \\
\hline Protium widgrenii & 10 & 6 & 0,550 & Trichilia catigua & 5 & 3 & 0,079 \\
\hline Ocotea elegans & 10 & 5 & 0,510 & Ocotea odorifera & 4 & 4 & 0,074 \\
\hline Aniba firmula & 18 & 4 & 0,495 & Roupala brasiliensis & 2 & 2 & 0,072 \\
\hline Sebastiania commersoniana & 29 & 8 & 0,457 & Pseudopiptadenia leptostachya & 2 & 2 & 0,071 \\
\hline Platycyamus regnellii & 3 & 3 & 0,333 & Mollinedia widgrenii & 3 & 2 & 0,066 \\
\hline Tabebuia umbellata & 3 & 2 & 0,298 & Siphoneugena densiflora & 5 & 3 & 0,063 \\
\hline Machaerium villosum & 1 & 1 & 0,296 & Heisteria silvianii & 4 & 3 & 0,059 \\
\hline Ocotea corymbosa & 1 & 1 & 0,269 & Ocotea glaziovii & 3 & 2 & 0,059 \\
\hline Galipea jasminiflora & 17 & 4 & 0,259 & Rollinia sericea & 1 & 1 & 0,059 \\
\hline Trichilia emarginata & 6 & 2 & 0,258 & Machaerium nictitans & 2 & 1 & 0,058 \\
\hline Myrciaria floribunda & 1 & 1 & 0,254 & Xylosma ciliatifolium & 2 & 2 & 0,057 \\
\hline Cariniana estrellensis & 1 & 1 & 0,244 & Cupania vernalis & 3 & 3 & 0,053 \\
\hline Nectandra cissiflora & 4 & 1 & 0,233 & Albizia polycephala & 2 & 2 & 0,045 \\
\hline Acacia polyphylla & $\begin{array}{l}4 \\
3\end{array}$ & $\begin{array}{l}1 \\
2\end{array}$ & 0,228 & Siparuna guianensis & 3 & 1 & 0,043 \\
\hline Persea pyrifolia & 1 & 1 & $\begin{array}{l}0,220 \\
0,224\end{array}$ & Myrsine intermedia & 3 & 2 & 0,042 \\
\hline Cabralea canjerana & $\begin{array}{l}1 \\
6\end{array}$ & $\begin{array}{l}1 \\
4\end{array}$ & $\begin{array}{l}0,224 \\
0,215\end{array}$ & Cytharexylum myrianthum & 2 & 1 & 0,042 \\
\hline $\begin{array}{l}\text { Cabralea canjerana } \\
\text { Cyathea phalerata }\end{array}$ & $\begin{array}{l}0 \\
9\end{array}$ & $\begin{array}{l}4 \\
3\end{array}$ & $\begin{array}{l}0,215 \\
0213\end{array}$ & Stylogyne ambigua & 2 & 2 & 0,036 \\
\hline $\begin{array}{l}\text { Cyathea phalerata } \\
\text { Genipa americana }\end{array}$ & 9 & $\begin{array}{l}3 \\
1\end{array}$ & 0,213 & Bauhinia longifolia & 2 & 1 & 0,036 \\
\hline $\begin{array}{l}\text { Genipa americana } \\
\text { Protium heptaphyllum }\end{array}$ & 4 & 1 & 0,211 & Xylosma prockia & 1 & 1 & 0,036 \\
\hline $\begin{array}{l}\text { Protium heptaphyllum } \\
\text { Croton floribundus }\end{array}$ & 3 & 2 & 0,186 & Clusia criuva & 1 & 1 & 0,034 \\
\hline Croton floribundus & 2 & 2 & 0,171 & Vismia brasiliensis & 1 & 1 & 0,029 \\
\hline Trichilia silvatica & 8 & 2 & 0,163 & Myrcia fallax & 3 & 2 & 0,027 \\
\hline Xylopia brasiliensis & 2 & 2 & 0,140 & Syagrus romanzoffiana & 1 & 1 & 0,027 \\
\hline Vitex megapotamica & 2 & 2 & 0,129 & syagrus romanzoJfiana & & & ontinua \\
\hline
\end{tabular}


continuação

\begin{tabular}{lccclccc}
\hline Espécie & $\mathrm{N}$ & $\mathrm{P}$ & $\mathrm{DoA}$ & Espécie & $\mathrm{N}$ & $\mathrm{P}$ & DoA \\
\hline Actinostemon klotzschii & 2 & 2 & 0,026 & Coutarea hexandra & 1 & 1 & 0,012 \\
Gomidesia affinis & 1 & 1 & 0,025 & Nectandra grandiflora & 1 & 1 & 0,011 \\
Eugenia involucrata & 3 & 3 & 0,024 & Marlierea racemosa & 1 & 1 & 0,011 \\
Amaioua guianensis & 2 & 2 & 0,024 & Rollinia laurifolia & 1 & 1 & 0,011 \\
Guatteria nigrescens & 2 & 1 & 0,022 & Gomidesia anacardiffolia & 1 & 1 & 0,011 \\
Psidium cattleianum & 1 & 1 & 0,022 & Ouratea semiserrata & 1 & 1 & 0,010 \\
Andira fraxinifolia & 2 & 2 & 0,021 & Calyptranthes lucida & 1 & 1 & 0,010 \\
Siphoneugena kuhlmannii & 2 & 2 & 0,021 & Duguetia lanceolata & 1 & 1 & 0,009 \\
Dalbergia villosa & 1 & 1 & 0,021 & 1 & 1 & 0,008 \\
Machaerium hirtum & 1 & 1 & 0,020 & Eugenia florida & 1 & 1 & 0,008 \\
Styrax camporum & 1 & 1 & 0,020 & Casearia decandra & 1 & 1 & 0,008 \\
Qualea multiflora & 2 & 2 & 0,018 & Ilex cognata & 1 & 1 & 0,008 \\
Ocotea aciphylla & 1 & 1 & 0,018 & Endlicheria paniculata & 1 & 1 & 0,008 \\
Machaerium lanceolatum & 1 & 1 & 0,018 & Piper arboreum & 1 & 1 & 0,006 \\
Cecropia glaziovii & 2 & 2 & 0,014 & Miconia tristis & 1 & 1 & 0,006 \\
Eugenia cerasiflora & 1 & 1 & 0,013 & Piper amalago & & & \\
\hline
\end{tabular}

gêneros mais ricos foram Ocotea (6 espécies), Trichilia (5), Machaerium (4), Eugenia, Piper e Protium (3 cada). 34\% das espécies apresentaram apenas um indivíduo. As famílias mais abundantes foram Magnoliaceae (146 indivíduos), Lauraceae (51), Clusiaceae (47) e Anacardiaceae (40). As espécies com maiores VI foram Talauma ovata, Calophyllum brasiliense, Tapirira obtusa, Dendropanax cuneatus, Copaifera langsdorffii e Sebastiania commersoniana. A floresta paludosa apresentou área basal de $36,13 \mathrm{~m}^{2} \cdot \mathrm{ha}^{-1}$, densidade de 1.828 indivíduos.ha ${ }^{-1}$, índice de Shannon de 3,50 e equabilidade de Pielou de 0,76.

No hábitat de encosta registraram-se 898 indivíduos, 130 espécies e 40 famílias (tabela 3). Destacaram-se Fabaceae (20 espécies), Lauraceae (15), Myrtaceae (14), Salicaceae (8) e Annonaceae (6), sendo 53\% das famílias com uma espécie. Os gêneros mais ricos foram Casearia e Ocotea (6 espécies cada), Nectandra (5), Eugenia, Machaerium e Trichilia (4 cada). 37\% das espécies apresentaram um só indivíduo. As famílias mais abundantes foram Rutaceae (230 indivíduos), Euphorbiaceae (161), Fabaceae (118) e Myrtaceae (90). Os maiores VI ocorreram nas espécies Ficus tomentella, Galipea jasminiflora, Sebastiania commersoniana, Metrodorea stipularis, Cryptocarya aschersoniana e Copaifera langsdorffii. A encosta apresentou área basal de $36,50 \mathrm{~m}^{2}$.ha-1, densidade de 1.321 indivíduos.ha-1 ${ }^{-1}$ índice de Shannon de 3,66 e equabilidade de 0,75 .

Identificaram-se seis subgrupos de solos na área de estudo: Cambissolos Háplicos Tb Distróficos gleicos,
Cambissolos Háplicos Ta Eutróficos gleicos, Cambissolos Háplicos Ta Eutróficos típicos, Latossolos Vermelhos Distróficos típicos, Latossolos Vermelhos Eutróficos típicos e Latossolos Vermelho-Amarelos Distróficos típicos. Os dois primeiros referem-se ao hábitat paludoso, onde a área é muito mal drenada, em nível topográfico inferior e com permanente afloramento do lençol freático. Os demais solos correspondem ao hábitat encosta, nas áreas superiores do terreno, sendo bem drenados (figura 1). Os dois hábitats diferiram significativamente para 6 das 19 variáveis comparadas (tabela 4). A área paludosa diferenciou-se da encosta principalmente por apresentar maiores valores de margem e menores valores de cota e, com menor importância, pelos valores inferiores de argila e potássio e de distância da borda do fragmento. Os dois hábitats não se diferenciaram estatisticamente em área basal, diâmetro e altura médios (tabela 4), mas pela maior densidade de árvores na área paludosa. Os dois hábitats exibiram um padrão de distribuição diamétrica semelhante (figura 2A), em J-reverso, ocorrendo as maiores classes de diâmetro $(>65 \mathrm{~cm})$ principalmente na encosta, mas com poucos indivíduos. O ambiente paludoso superou a encosta em freqüência percentual nos intervalos entre $15-35 \mathrm{~cm}$ e $45-55 \mathrm{~cm}$ de diâmetro. A distribuição altimétrica (figura 2B) mostrou um padrão em que a encosta supera o hábitat paludoso apenas nas menores e maiores classes de altura.

A CCA apresentou variâncias acumuladas para espécies relativamente baixas (27,9; 38,2 e 43,9\% para os três primeiros eixos; autovalores respectivos de 0,56 ; 
Tabela 3. Espécies arbóreas amostradas em 17 parcelas de $20 \times 20$ m em hábitat de encosta de uma floresta ripária em Coqueiral, MG, e quantitativos: $\mathrm{N}=$ número de indivíduos, $\mathrm{P}=$ número de parcelas com ocorrência da espécie e DoA = dominância absoluta $\left(\mathrm{m}^{2} \cdot \mathrm{ha}^{-1}\right)$. Espécies ordenadas por DoA decrescente.

Table 3. Tree species surveyed in 17 sample plots of $20 \times 20 \mathrm{~m}$ of dimensions in the sloping habitat of an area of riparian forest in Coqueiral, SE Brazil, and their quantitative parameters: $\mathrm{N}=$ number of individuals, $\mathrm{P}=$ number of sample plots with the species, and DoA $=$ absolute dominance $\left(\mathrm{m}^{2} \cdot \mathrm{ha}^{-1}\right)$. Species ranked by decreasing DoA.

\begin{tabular}{|c|c|c|c|c|c|c|c|}
\hline Espécie & $\mathrm{N}$ & $\mathrm{P}$ & DoA & Espécie & $\mathrm{N}$ & $\mathrm{P}$ & DoA \\
\hline Ficus tomentella & 6 & 5 & 11,557 & Roupala brasiliensis & 2 & 2 & 0,087 \\
\hline Metrodorea stipularis & 57 & 13 & 3,593 & Ocotea glaziovii & 2 & 2 & 0,087 \\
\hline Cryptocarya aschersoniana & 13 & 8 & 3,377 & Croton floribundus & 4 & 2 & 0,085 \\
\hline Aspidosperma polyneuron & 6 & 5 & 1,853 & Calycorectes acutatus & 1 & 1 & 0,077 \\
\hline Copaifera langsdorffii & 36 & 11 & 1,731 & Ficus pertusa & 1 & 1 & 0,014 \\
\hline Sebastiania commersoniana & 150 & 14 & 1,094 & Citronella paniculata & 1 & 1 & 0,014 \\
\hline Galipea jasminiflora & 158 & 14 & 0,997 & Nectandra cissiflora & 2 & 2 & 0,013 \\
\hline Myroxylon peruiferum & 1 & 1 & 0,841 & Talauma ovata & 2 & 1 & 0,013 \\
\hline Trichilia emarginata & 15 & 6 & 0,711 & Xylopia brasiliensis & 1 & 1 & 0,013 \\
\hline Pseudopiptadenia leptostachya & 13 & 7 & 0,613 & Cecropia glaziovii & 1 & 1 & 0,013 \\
\hline Miconia argyrophylla & 30 & 6 & 0,490 & Andira fraxinifolia & 3 & 3 & 0,012 \\
\hline Myrcia fallax & 31 & 8 & 0,443 & Machaerium hirtum & 2 & 2 & 0,012 \\
\hline Ocotea odorifera & 8 & 5 & 0,434 & Connarus regnellii & 1 & 1 & 0,012 \\
\hline Machaerium nictitans & 10 & 3 & 0,433 & Maprounea guianensis & 1 & 1 & 0,011 \\
\hline Alseis floribunda & 4 & 2 & 0,400 & Marlierea racemosa & 1 & 1 & 0,010 \\
\hline Malouetia arborea & 1 & 1 & 0,379 & Miconia cinerascens & 2 & 1 & 0,009 \\
\hline Siphoneugena densiflora & 17 & 7 & 0,357 & Ormosia arborea & 2 & 1 & 0,009 \\
\hline Aniba firmula & 6 & 5 & 0,347 & Licania octandra & 1 & 1 & 0,008 \\
\hline Acacia polyphylla & 7 & 3 & 0,327 & Endlicheria paniculata & 1 & 1 & 0,008 \\
\hline Luehea divaricata & 6 & 4 & 0,295 & Ilex cerasifolia & 2 & 2 & 0,007 \\
\hline Trichilia clausseni & 11 & 1 & 0,273 & Esenbeckia leiocarpa & 2 & 1 & 0,076 \\
\hline Machaerium villosum & 10 & 3 & 0,256 & Inga marginata & 4 & 1 & 0,075 \\
\hline Salacia elliptica & 4 & 2 & 0,228 & Duguetia lanceolata & 1 & 1 & 0,074 \\
\hline Tabebuia serratifolia & 2 & 2 & 0,226 & Inga striata & 1 & 1 & 0,071 \\
\hline Ocotea diospyrifolia & 5 & 4 & 0,220 & Siparuna guianensis & 14 & 7 & 0,069 \\
\hline Psidium robustum & 8 & 5 & 0,209 & Casearia sylvestris & 5 & 4 & 0,067 \\
\hline Plinia grandifolia & 1 & 1 & 0,186 & Nectandra grandiflora & 3 & 3 & 0,065 \\
\hline Actinostemon klotzschii & 5 & 4 & 0,177 & Schefflera calva & 1 & 1 & 0,062 \\
\hline Savia dictyocarpa & 1 & 1 & 0,177 & Cabralea canjerana & 2 & 2 & 0,060 \\
\hline Eugenia handroana & 5 & 2 & 0,166 & Rollinia laurifolia & 1 & 1 & 0,055 \\
\hline Zanthoxylum petiolare & 7 & 4 & 0,157 & Xylosma prockia & 2 & 1 & 0,054 \\
\hline Eugenia excelsa & 9 & 3 & 0,144 & Protium heptaphyllum & 2 & 2 & 0,053 \\
\hline Machaerium brasiliense & 4 & 2 & 0,134 & Vochysia magnifica & 1 & 1 & 0,053 \\
\hline Chrysophyllum gonocarpum & 5 & 3 & 0,131 & Trichilia catigua & 5 & 3 & 0,047 \\
\hline Ocotea elegans & 8 & 6 & 0,129 & Hymenaea courbaril & 5 & 2 & 0,045 \\
\hline Platypodium elegans & 11 & 3 & 0,119 & Casearia obliqua & 1 & 1 & 0,045 \\
\hline Mollinedia widgrenii & 8 & 7 & 0,118 & Trichilia pallida & 6 & 4 & 0,044 \\
\hline Psidium rufum & 7 & 5 & 0,104 & Senna macranthera & 1 & 1 & 0,044 \\
\hline Cariniana legalis & 1 & 1 & 0,100 & Matayba elaeagnoides & 1 & 1 & 0,041 \\
\hline Tapirira guianensis & 5 & 2 & 0,098 & Annona cacans & 1 & 1 & 0,039 \\
\hline Protium widgrenii & 3 & 3 & 0,096 & Lafoensia pacari & 3 & 1 & 0,036 \\
\hline Cupania vernalis & 4 & 3 & 0,094 & Psychotria vellosiana & 8 & 5 & 0,034 \\
\hline Zanthoxylum rhoifolium & 6 & 5 & 0,092 & Persea pyrifolia & 2 & 2 & 0,034 \\
\hline Tapirira obtusa & 6 & 4 & 0,090 & Casearia aculeata & 6 & 5 & 0,033 \\
\hline Sweetia fruticosa & 1 & 1 & 0,089 & Nectandra oppositifolia & 2 & 1 & 0,032 \\
\hline
\end{tabular}


continuação

\begin{tabular}{llllllll}
\hline Espécie & $\mathrm{N}$ & $\mathrm{P}$ & DoA & Espécie & $\mathrm{N}$ & $\mathrm{P}$ & DoA \\
\hline Casearia ulmifolia & 4 & 3 & 0,031 & Aralia warmingiana & 1 & 1 & 0,017 \\
Alchornea glandulosa & 1 & 1 & 0,030 & Eugenia cerasiflora & 2 & 2 & 0,016 \\
Solanum cernuum & 5 & 3 & 0,027 & Albizia polycephala & 1 & 1 & 0,014 \\
Bauhinia longifolia & 4 & 3 & 0,027 & Xylopia aromatica & 1 & 1 & 0,014 \\
Campomanesia velutina & 4 & 2 & 0,026 & Miconia latecrenata & 2 & 1 & 0,007 \\
Pouteria glomerata & 2 & 1 & 0,026 & Siphoneugena kuhlmannii & 1 & 1 & 0,007 \\
Nectandra lanceolata & 1 & 1 & 0,026 & Zygia latifolia & 1 & 1 & 0,007 \\
Vernonanthura diffusa & 1 & 1 & 0,024 & Piper arboreum & 1 & 1 & 0,007 \\
Seguieria langsdorffii & 2 & 2 & 0,023 & Ocotea indecora & 1 & 1 & 0,006 \\
Ocotea pulchella & 1 & 1 & 0,023 & Casearia lasiophylla & 1 & 1 & 0,006 \\
Vochysia tucanorum & 2 & 1 & 0,022 & Alibertia concolor & 1 & 1 & 0,005 \\
Ixora warmingii & 4 & 3 & 0,021 & Sorocea bonplandii & 1 & 1 & 0,004 \\
Casearia decandra & 3 & 2 & 0,021 & Myrsine coriacea & 1 & 1 & 0,004 \\
Matayba juglandifolia & 2 & 1 & 0,021 & Qualea multiflora & 1 & 1 & 0,003 \\
Eugenia florida & 2 & 1 & 0,021 & Guatteria nigrescens & 1 & 1 & 0,003 \\
Dendropanax cuneatus & 3 & 3 & 0,020 & Nectandra megapotamica & 1 & 1 & 0,003 \\
Xylosma ciliatifolium & 3 & 2 & 0,020 & Cybistax antisyphillitica & 1 & 1 & 0,003 \\
Amaioua guianensis & 2 & 2 & 0,020 & Lacistema hasslerianum & 1 & 1 & 0,003 \\
Heisteria silvianii & 4 & 2 & 0,019 & Platycyamus regnellii & 1 & 1 & 0,003 \\
Gomidesia anacardiifolia & 1 & 1 & 0,019 & Leandra scabra & 1 & 1 & 0,003 \\
\hline
\end{tabular}

Tabela 4. Comparação entre médias das variáveis topográficas, edáficas e estruturais fisionômicas amostradas em 25 parcelas de $20 \times 20 \mathrm{~m}$ em dois hábitats de uma floresta ripária em Coqueiral, MG. Valores são médias \pm desvios padrão das n amostras de cada hábitat. $* \mathrm{p}<0.05 ; * * \mathrm{p}<0.01 ; * * * \mathrm{p}<0.001 ; \mathrm{ns}=$ não significativo.

Table 4. Comparisons among means of the topographic, edaphic and structural-physiognomic variables sampled in 25 sample plots of $20 \times 20 \mathrm{~m}$ of dimensions in the two habitats of an area of riparian forest in Coqueiral, SE Brazil. Values are means \pm standard deviations of the $\mathrm{n}$ samples of each habitat. $* \mathrm{p}<0.05 ; * * \mathrm{p}<0.01 ; * * * \mathrm{p}<0.001$; ns $=$ not significant.

\begin{tabular}{|c|c|c|c|c|c|}
\hline \multirow[b]{2}{*}{ Variáveis } & \multirow{2}{*}{$\begin{array}{l}\text { Total } \\
\mathrm{n}=25\end{array}$} & \multirow{2}{*}{$\begin{array}{l}\text { Hábitat paludoso } \\
\qquad \mathrm{n}=8\end{array}$} & \multirow{2}{*}{$\begin{array}{l}\text { Hábitat de encosta } \\
\qquad \mathrm{n}=17\end{array}$} & \multicolumn{2}{|c|}{ ANOVA } \\
\hline & & & & $\mathrm{F}$ & $\mathrm{p}$ \\
\hline Cota média (m) & $822 \pm 9$ & $813 \pm 1$ & $827 \pm 7$ & 37,94 & $<10^{-3} * * *$ \\
\hline Margem (m) & $92 \pm 89$ & $190 \pm 21$ & $46 \pm 68$ & 33,49 & $<10^{-3} * * *$ \\
\hline Desnível (m) & $3,7 \pm 1,0$ & $3,4 \pm 1,1$ & $3,9 \pm 1,0$ & 1,07 & $0,311 \mathrm{~ns}$ \\
\hline Borda (m) & $97 \pm 77$ & $49 \pm 69$ & $119 \pm 72$ & 5,34 & $0,030 *$ \\
\hline $\mathrm{pHem} \mathrm{H}_{2} \mathrm{O}$ & $5,2 \pm 0,7$ & $5,3 \pm 0,8$ & $5,2 \pm 0,6$ & 0,13 & $0,719 \mathrm{~ns}$ \\
\hline P-Mehlich (mg.dm $\left.{ }^{-3}\right)$ & $1,4 \pm 0,5$ & $1,5 \pm 0,5$ & $1,4 \pm 0,5$ & 0,17 & $0,684 \mathrm{~ns}$ \\
\hline $\mathrm{K}\left(\mathrm{mg} \cdot \mathrm{dm}^{-3}\right)$ & $78 \pm 32$ & $60 \pm 31$ & $87 \pm 30$ & 4,31 & $0,049 *$ \\
\hline $\mathrm{Ca}^{2+}\left(\mathrm{cmol}_{\mathrm{c}} \cdot \mathrm{dm}^{-3}\right)$ & $3,1 \pm 4,7$ & $4,9 \pm 6,8$ & $2,3 \pm 3,2$ & 1,75 & $0,199 \mathrm{~ns}$ \\
\hline $\mathrm{Mg}^{2+}\left(\mathrm{cmol}_{\mathrm{c}} \cdot \mathrm{dm}^{-3}\right)$ & $1,1 \pm 0,9$ & $0,9 \pm 0,8$ & $1,1 \pm 1,0$ & 0,23 & $0,633 \mathrm{~ns}$ \\
\hline $\mathrm{Al}^{3+}\left(\mathrm{cmol}_{c^{\prime}} \cdot \mathrm{dm}^{-3}\right)$ & $1,0 \pm 0,9$ & $1,0 \pm 1,1$ & $1,1 \pm 0,8$ & 0,04 & $0,837 \mathrm{~ns}$ \\
\hline $\mathrm{V}(\%)$ & $34 \pm 28$ & $39 \pm 33$ & $32 \pm 26$ & 0,30 & $0,591 \mathrm{~ns}$ \\
\hline $\mathrm{MO}\left(\right.$ dag. $\left.\mathrm{kg}^{-1}\right)$ & $3,6 \pm 1,2$ & $4,2 \pm 1,7$ & $3,3 \pm 0,7$ & 3,38 & $0,079 \mathrm{~ns}$ \\
\hline Areia $(\%)$ & $20 \pm 6$ & $21 \pm 9$ & $19 \pm 5$ & 0,57 & $0,459 \mathrm{~ns}$ \\
\hline Silte (\%) & $24 \pm 9$ & $29 \pm 8$ & $22 \pm 8$ & 4,23 & $0,051 \mathrm{~ns}$ \\
\hline Argila (\%) & $56 \pm 10$ & $50 \pm 13$ & $59 \pm 7$ & 5,54 & $0,027 *$ \\
\hline Densidade (ind.ha-1 ${ }^{-1}$ ) & $1483 \pm 417$ & $1828 \pm 546$ & $1321 \pm 211$ & 11,52 & $0,002 * *$ \\
\hline Área basal $\left(\mathrm{m}^{2} \cdot \mathrm{ha}^{-1}\right)$ & $36,4 \pm 27,1$ & $36,1 \pm 15,1$ & $36,5 \pm 31,6$ & 0,001 & $0,975 \mathrm{~ns}$ \\
\hline $\mathrm{DAP}(\mathrm{cm})$ & $12,6 \pm 1,9$ & $12,9 \pm 1,5$ & $12,5 \pm 2,1$ & 0,25 & $0,619 \mathrm{~ns}$ \\
\hline Altura (m) & $9,1 \pm 1,3$ & $9,6 \pm 1,2$ & $8,8 \pm 1,4$ & 1,63 & $0,215 \mathrm{~ns}$ \\
\hline
\end{tabular}


$0,17$ e 0,09$)$. No entanto, os valores de correlação entre variáveis ambientais e espécies foram altos $(95 \% ; 91 \%$ e 85\%). O teste de permutação de Monte Carlo revelou correlação significativa entre abundâncias de espécies e variáveis ambientais apenas para o primeiro eixo ( $p<0,01$; seguido de 0,08 e 0,46 para eixos 2 e 3). O primeiro eixo da ordenação explicou a maior parte da variação. As correlações entre variáveis ambientais e parcelas indicaram três grupos (figura $3 \mathrm{~A}$ ): o primeiro formado por parcelas mais próximas do lago, com alto teor de $\mathrm{MO}$ e silte, e elevado $\mathrm{pH}$, nutricionalmente rico e menos drenado; o segundo grupo, intermediário, e o terceiro grupo tipicamente bem drenado, alocado em sítios topográficos mais altos, com alto teor de $\mathrm{Al}^{3+} \mathrm{e}$ argila, em solos de menor fertilidade que os demais. A

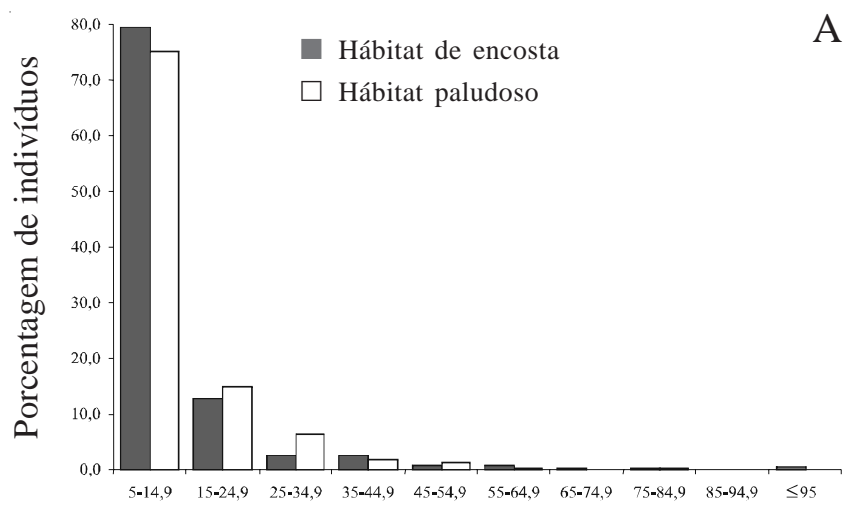

Classe de diâmetro $(\mathrm{cm})$

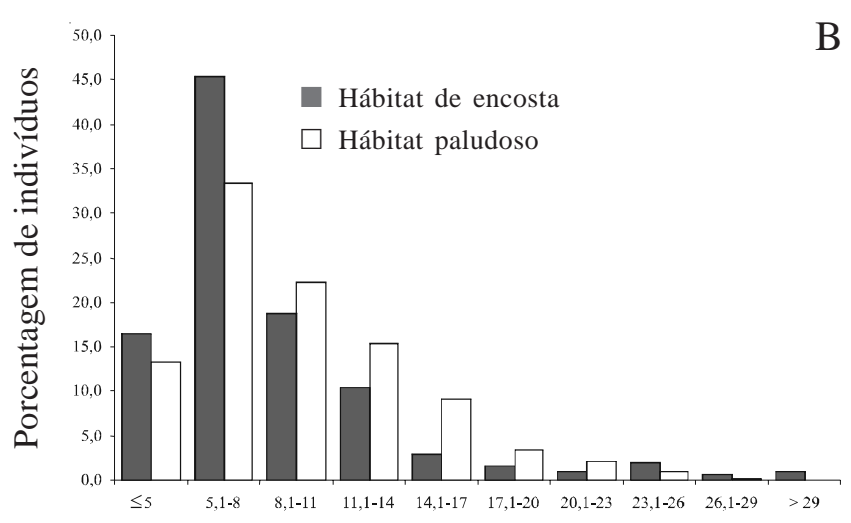

Classe de altura (m)

Figura 2. Distribuição de freqüências percentuais dos diâmetros (A) e alturas (B) dos indivíduos arbóreos amostrados em dois hábitats, de encosta $(n=898)$ e paludoso $(\mathrm{n}=585)$, em uma floresta ripária em Coqueiral, $\mathrm{MG}$.

Figure 2. Percent frequency distribution of diameters (A) and heights (B) of individual trees sampled in the swampy $(n=585)$ and sloping $(n=898)$ habitats of an area of riparian forest in Coqueiral, SE Brazil.

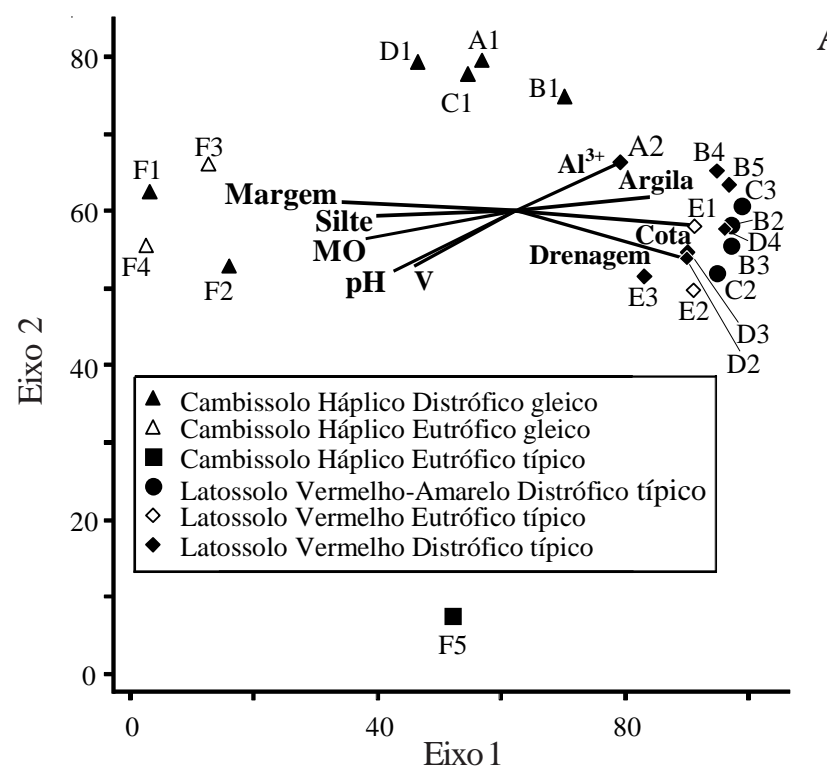

A

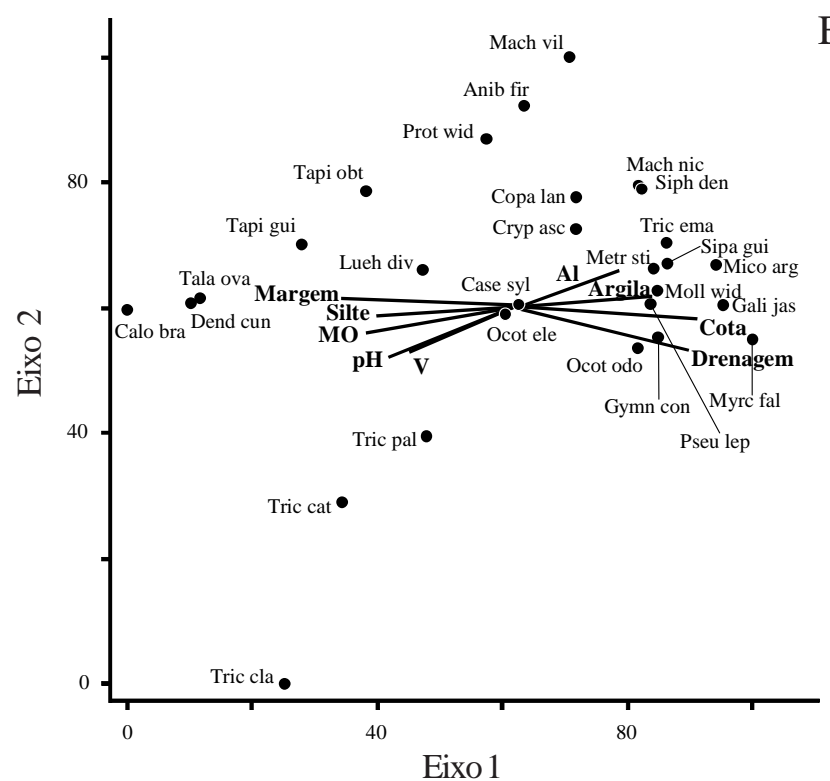

Figura 3. Diagrama de ordenação, produzido por análise de correspondência canônica (CCA), da abundância de 29 espécies amostradas em 22 parcelas, em floresta ripária em Coqueiral, MG. Nos diagramas encontram-se a distribuição das parcelas e variáveis ambientais (A) e a distribuição das espécies (identificadas por suas iniciais) e variáveis ambientais (B), ambos nos dois primeiros eixos de ordenação. Linhas contínuas indicam grandeza e sentido de aumento das variáveis ambientais.

Figure 3. Ordination diagram produced by canonical correspondence analysis (CCA) of the abundance of 29 species sampled in 22 plots in an area of riparian forest in Coqueiral, SE Brazil. Diagrams show the distribution of plots and environmental variables (A) and the distribution of species (identified by their abbreviated names) and environmental variables (B), both in the two ordination diagrams. Continuous lines represent the weight and direction of increasing environmental variables. 
cada grupo correlacionou-se um grupo de espécies (figura 3B). Associaram-se ao primeiro grupo, espécies como Calophyllum brasiliense, Talauma ovata e Dendropanax cuneatus; ao segundo Luehea divaricata, Protium widgrenii e Aniba firmula; e ao último, Galipea jasminiflora, Sebastiania commersoniana e Siparuna guianensis, entre outras. Grande número de correlações espécie-ambiente encontradas pela CCA foram confirmadas pelos coeficientes de Spearman, conforme tabela 5. As três parcelas inicialmente retiradas da CCA formaram um grupo de espécies típicas de cerrado, como Xylopia aromatica, Qualea multiflora, Heteropterys byrsonimifolia, Bowdichia virgilioides, Zeyheria tuberculosa e Tabebuia ochracea, sobre Latossolo Vermelho Distrófico, relacionados às variáveis ambientais à direita na figura $3 \mathrm{~A}$.

\section{Discussão}

A floresta ripária estudada compõe um mosaico de vegetação associada à grande diversidade ambiental, apesar do reduzido tamanho do fragmento. A diversidade de solos e regimes de umidade associados ao gradiente topográfico somam-se à presença de espécies de fitofisionomias do entorno e variação na disponibilidade de luz. Esse conjunto influencia a composição e diversidade de espécies. A influência da vegetação adjacente é notada na ocorrência de espécies de cerrado na borda do fragmento. Assim, a mata de Coqueiral destacou-se por apresentar elevada riqueza de espécies quando comparada com outros nove levantamentos na região do Alto e Médio Rio Grande, com esforço amostral similar. Destes, apenas o levantamento de Tiradentes, com 277 espécies em cerca de 1.000 ha (Oliveira Filho \& Machado 1993) superou a riqueza apresentada pela mata de Coqueiral, com 242 espécies em 10 ha, o que provavelmente se deve à grande diferença de tamanho dos fragmentos. As demais áreas são Poço Bonito, 219 espécies em 74 ha (Oliveira Filho et al. 1994a); Reserva Florestal da UFLA, 184 em 6 ha (Oliveira Filho et al. 1994b); Madre de Deus de Minas, 192 em 20 ha (Oliveira Filho et al. 1994c); Bom Sucesso, 219 em 84 ha (Carvalho et al. 1992, 1995); Itutinga, 162 em 7,6 ha (van den Berg \& Oliveira Filho 2000); Mata da Ilha, 212 em 17 ha (Botrel et al. 2002); Subestação, 238 em 8,8 ha (Espírito-Santo et al. 2002) e Capivari, 165 em 13,6 ha (Souza et al. 2003).

O perfil florístico encontrado (sensu Leitão Filho 1987, ou seja, o conjunto de espécies caracterizadoras da fisionomia vegetal) é bastante similar ao da maioria das matas ciliares levantadas no Alto e Médio Rio Grande (Carvalho et al. 1995, 1996, 2000, Oliveira Filho et al. 1994a, b, Souza et al. 2003, Botrel et al. 2002). Além disso, das nove espécies mais comuns em matas ciliares, levantadas a partir de 43 levantamentos por Rodrigues \& Nave (2000), apenas Luehea divaricata e Cecropia pachystachya não foram encontradas na mata de Coqueiral. No entanto, a porção de floresta paludosa diferenciou-se do padrão encontrado na literatura. Destacou-se principalmente pela elevada riqueza: 99 espécies e 35 famílias em uma amostragem de 585 indivíduos e 0,32 ha, para uma área brejosa de aproximadamente 0,7 ha. Em Campinas foram 33 espécies e 23 famílias em 930 indivíduos e 0,87 ha (Torres et al. 1994); outra área em Campinas, 55 espécies, 29 famílias, 955 indivíduos e 0,20 ha (Toniato et al. 1998); Itatinga, 41 espécies, 28 famílias, 1.350 indivíduos e 1 ha (Ivanauskas et al. 1997); Agudos, 38 espécies, 23 famílias, 1.116 indivíduos e 0,22 ha (Paschoal \& Cavassan 1999); variando estas áreas de brejo entre 0,9 e 5 ha. Desconsiderando a área paludosa de transição entre os dois hábitats em Coqueiral, as parcelas F1 a F4 isoladamente ainda revelam alta diversidade: 61 espécies e 31 famílias em amostragem de apenas 316 indivíduos e 0,16 ha. Esse artifício é inadequado na comparação, já que outros trabalhos também consideraram e observaram a marcante influência florística de formações adjacentes sobre a mata paludosa (Torres et al. 1992, 1994, Ivanauskas et al. 1997). Porém, o menor número de espécies exclusivas deste hábitat reforça a afirmação de Ivanauskas et al. (1997), de que quanto maior o encharcamento menor a diversidade. As matas paludosas têm sido caracterizadas como formações naturalmente fragmentadas com baixa diversidade (Paschoal \& Cavassan 1999). Porém, a porção de mata paludosa estudada apresentou o maior índice de Shannon $\left(\mathrm{H}^{\prime}=3,50\right)$ em relação às outras áreas estudadas no Sudeste: 2,45 e 2,80 em Campinas, 2,75 em Itatinga e 2,60 em Agudos. Se retirada a área de transição, encontra-se $H^{\prime}=2,76$, próximo das demais áreas.

A área basal dos hábitats de encosta e paludoso (respectivamente de 36,50 e 36,13 $\mathrm{m}^{2}$.ha-1), comparada com os outros levantamentos na região já citados usando o mesmo diâmetro mínimo, assemelhou-se apenas a Bom Sucesso $\left(34,99 \mathrm{~m}^{2} \cdot \mathrm{ha}^{-1}\right)$, superando Capivari (31,03), Mata da Ilha $(29,31)$, Subestação $(27,24)$ e Reserva da UFLA $(19,77)$. A densidade na encosta (1.321 árvores.ha ${ }^{-1}$ ) aproximou-se à Reserva da UFLA (1.295 árvores.ha ${ }^{-1}$ e ficou abaixo de Capivari (1.487), 
Tabela 5. Coeficientes de correlação de Spearman entre a abundância das 29 espécies empregadas na CCA e as variáveis drenagem, V, MO, cota e margem, em floresta ripária em Coqueiral, MG. $\mathrm{N}=$ número de indivíduos na amostra total. * p < 0,05 ; $* * \mathrm{p}<0,01 ; * * * \mathrm{p}<0,001 ; \mathrm{ns}=$ não significativo.

Table 5. Spearman correlation coefficients between the abundance of the 29 tree species used in canonical correspondence analysis (CCA) and the variables drainage, soil saturation of bases, organic matter, elevation and margin, in an area of riparian forest in Coqueiral, SE Brazil. $\mathrm{N}=$ number of individuals in total sample. $* \mathrm{p}<0,05 ; * * \mathrm{p}<0,01 ; * * * \mathrm{p}<0,001 ; \mathrm{ns}=$ not significant.

\begin{tabular}{|c|c|c|c|c|c|c|c|}
\hline Espécies & $\mathrm{N}$ & Drenagem & $\mathrm{V}$ & & MO & Cota & Margem \\
\hline Sebastiania commersoniana & 179 & $-0,03 \mathrm{~ns}$ & 0,08 & $\mathrm{~ns}$ & $-0,05 \mathrm{~ns}$ & $0,01 \mathrm{~ns}$ & $-0,04 \mathrm{~ns}$ \\
\hline Aniba firmula & 24 & $-0,37 \mathrm{~ns}$ & $-0,34$ & $\mathrm{~ns}$ & $-0,17 \mathrm{~ns}$ & $-0,21 \mathrm{~ns}$ & $0,21 \mathrm{~ns}$ \\
\hline Calophyllum brasiliense & 45 & $-0,72 * * *$ & 0,22 & $\mathrm{~ns}$ & $0,50 *$ & $-0,73 * * *$ & $0,74 * * *$ \\
\hline Casearia sylvestris & 10 & $-0,04 \mathrm{~ns}$ & $-0,13$ & $\mathrm{~ns}$ & $-0,25 \mathrm{~ns}$ & $0,06 \mathrm{~ns}$ & $-0,02 \mathrm{~ns}$ \\
\hline Copaifera langsdorffii & 49 & $0,11 \mathrm{~ns}$ & $-0,57$ & $* *$ & $-0,7 \quad * * *$ & $0,28 \mathrm{~ns}$ & $-0,32 \mathrm{~ns}$ \\
\hline Cryptocarya aschersoniana & 18 & $0,19 \mathrm{~ns}$ & $-0,53$ & $* *$ & $-0,21 \mathrm{~ns}$ & $0,03 \mathrm{~ns}$ & $-0,11 \mathrm{~ns}$ \\
\hline Dendropanax cuneatus & 34 & $-0,71 * * *$ & 0,22 & $\mathrm{~ns}$ & $0,30 \mathrm{~ns}$ & $-0,64 * * *$ & $0,69 * * *$ \\
\hline Galipea jasminiflora & 175 & $0,45 *$ & $-0,23$ & $\mathrm{~ns}$ & $-0,14 \mathrm{~ns}$ & $0,41 *$ & $-0,42 *$ \\
\hline Luehea divaricata & 11 & $-0,01 \mathrm{~ns}$ & $-0,02$ & $\mathrm{~ns}$ & $-0,27 \mathrm{~ns}$ & $0,00 \mathrm{~ns}$ & $0,03 \mathrm{~ns}$ \\
\hline Machaerium nictitans & 12 & $0,13 \mathrm{~ns}$ & $-0,29$ & $\mathrm{~ns}$ & $-0,43 *$ & $0,24 \mathrm{~ns}$ & $-0,23 \mathrm{~ns}$ \\
\hline Machaerium villosum & 11 & $0,19 \mathrm{~ns}$ & $-0,38$ & $\mathrm{~ns}$ & $-0,45 *$ & $0,30 \mathrm{~ns}$ & $-0,29 \mathrm{~ns}$ \\
\hline Metrodorea stipularis & 70 & $0,22 \mathrm{~ns}$ & $-0,04$ & $\mathrm{~ns}$ & $-0,11 \mathrm{~ns}$ & $0,32 \mathrm{~ns}$ & $-0,32 \mathrm{~ns}$ \\
\hline Miconia argyrophylla & 31 & $0,33 \mathrm{~ns}$ & $-0,36$ & $\mathrm{~ns}$ & $-0,48 *$ & $0,37 \mathrm{~ns}$ & $-0,41 *$ \\
\hline Mollinedia widgrenii & 11 & $0,21 \mathrm{~ns}$ & 0,01 & $\mathrm{~ns}$ & $0,01 \mathrm{~ns}$ & $0,17 \mathrm{~ns}$ & $-0,22 \mathrm{~ns}$ \\
\hline Myrcia fallax & 34 & $0,36 \mathrm{~ns}$ & $-0,57$ & $* *$ & $-0,18 \mathrm{~ns}$ & $0,28 \mathrm{~ns}$ & $-0,22 \mathrm{~ns}$ \\
\hline Ocotea elegans & 18 & $-0,25 \mathrm{~ns}$ & $-0,20$ & $\mathrm{~ns}$ & $0,18 \mathrm{~ns}$ & $-0,34 \mathrm{~ns}$ & $0,33 \mathrm{~ns}$ \\
\hline Ocotea oodorifera & 12 & $-0,17 \mathrm{~ns}$ & 0,10 & $\mathrm{~ns}$ & $-0,01 \mathrm{~ns}$ & $-0,3 \mathrm{~ns}$ & $0,19 \mathrm{~ns}$ \\
\hline Platypodium elegans & 11 & $0,29 \mathrm{~ns}$ & $-0,30$ & $\mathrm{~ns}$ & $-0,31 \mathrm{~ns}$ & $0,38 \mathrm{~ns}$ & $-0,37 \mathrm{~ns}$ \\
\hline Protium widgrenii & 13 & $-0,63 * * *$ & $-0,18$ & $\mathrm{~ns}$ & $-0,10 \mathrm{~ns}$ & $-0,45 *$ & $0,46 *$ \\
\hline Pseudopiptadenia leptostachya & 15 & $0,12 \mathrm{~ns}$ & $-0,06$ & $\mathrm{~ns}$ & $0,08 \mathrm{~ns}$ & $0,06 \mathrm{~ns}$ & $-0,13 \mathrm{~ns}$ \\
\hline Siparuna guianensis & 17 & $0,32 \mathrm{~ns}$ & $-0,33$ & $\mathrm{~ns}$ & $-0,36 \mathrm{~ns}$ & $0,50 *$ & $-0,48 *$ \\
\hline Siphoneugena densiflora & 22 & $0,08 \mathrm{~ns}$ & $-0,09$ & $\mathrm{~ns}$ & $-0,12 \mathrm{~ns}$ & $0,15 \mathrm{~ns}$ & $-0,24 \mathrm{~ns}$ \\
\hline Talauma ovata & 148 & $-0,89 * * *$ & 0,24 & $\mathrm{~ns}$ & $0,41 *$ & $-0,85 * * *$ & $0,88 * * *$ \\
\hline Tapirira guianensis & 16 & $-0,36 \mathrm{~ns}$ & $-0,23$ & $\mathrm{~ns}$ & $-0,13 \mathrm{~ns}$ & $-0,34 \mathrm{~ns}$ & $0,32 \mathrm{~ns}$ \\
\hline Tapirira obtusa & 35 & $-0,7 \quad * * *$ & $-0,11$ & $\mathrm{~ns}$ & $-0,02 \mathrm{~ns}$ & $-0,61 * *$ & $0,58 * *$ \\
\hline Trichilia catigua & 10 & $-0,23 \mathrm{~ns}$ & 0,59 & $* *$ & $0,38 \mathrm{~ns}$ & $-0,41 \quad *$ & $0,41 *$ \\
\hline Trichilia clausseni & 15 & $-0,25 \mathrm{~ns}$ & 0,46 & $*$ & $0,45 *$ & $-0,47 *$ & $0,56 * *$ \\
\hline Trichilia emarginata & 21 & $-0,02 \mathrm{~ns}$ & $-0,14$ & $\mathrm{~ns}$ & $-0,05 \mathrm{~ns}$ & $0,00 \mathrm{~ns}$ & $0,02 \mathrm{~ns}$ \\
\hline Trichilia pallida & 11 & $-0,11 \mathrm{~ns}$ & 0,34 & $\mathrm{~ns}$ & $0,42 *$ & $-0,50 *$ & $0,52 * *$ \\
\hline
\end{tabular}

Subestação (1.500), Mata da Ilha (2.383) e Bom Sucesso (2.063); enquanto o hábitat paludoso situou-se em posição intermediária (1.828 árvores.ha $\left.{ }^{-1}\right)$. A estrutura em Coqueiral reflete uma densidade média a baixa com árvores grandes, sugerindo um fragmento mais preservado e maduro. Os índices de diversidade de Shannon encontrados nos hábitats de encosta $\mathrm{e}$ paludoso (3,66 e 3,50, respectivamente) foi um dos menores encontrados na região do Alto e Médio Rio Grande, devido à baixa equabilidade $(0,75$ e 0,76$)$. Isto reflete um processo de dominância ecológica, existente nos dois hábitats, destacando-se no hábitat paludoso,
Talauma ovata, Calophyllum brasiliense e Dendropanax cuneatus, e na encosta Galipea jasminiflora, Sebastiania commersoniana e Metrodorea stipularis.

A drenagem dos solos e a proximidade da margem da lagoa, segundo a CCA, foram as variáveis que mais contribuíram para a divisão dos grupos de parcelas e espécies nos dois hábitats. A segunda, embora também se correlacione com a presença de água no solo, agrega ainda a influência da luminosidade. A área de transição sobre solos brejosos revelou uma terceira situação, compondo um ecótono, com drenagem variável de muito 
mal drenado a imperfeitamente drenado, e espécies típicas dos dois ambientes, porém mais próximas do paludoso. Talauma ovata e Calophyllum brasiliense, exclusivas da área paludosa, são consideradas espécies indicadoras desta vegetação (Paschoal \& Cavassan 1999), presentes em todos os levantamentos em florestas paludosas no Estado de São Paulo. Juntamente com Dendropanax cuneatus, as três são as mais importantes no hábitat paludoso em Coqueiral. Espécies como Sebastiania commersoniana, Galipea jasminiflora e Metrodorea stipularis, caracterizadas pelas maiores freqüências, apresentaram preferência pela encosta. G. jasminiflora apresentou-se como tipicamente de ambiente bem drenado, discordando de Lorenzi (1992), que a classifica como espécie de ambiente mal drenado. Copaifera langsdorffi ocorreu indiferentemente nos dois hábitats, reforçando seu destaque no Alto e Médio Rio Grande pela elevada abundância e caráter generalista (Oliveira Filho et al. 1994b, van den Berg \& Oliveira Filho 1999). Porém, juntamente com Myrcia fallax e Cryptocarya aschersoniana, correlacionaram-se com solos menos férteis. Vários resultados confirmaram observações de Oliveira Filho \& Ratter (2000): Tapirira guianensis, de ampla distribuição nos Neotrópicos, ocorrendo em vários hábitats e formações, foi amostrada em todo o fragmento; Maprounea guianensis ocorreu preferencialmente na borda; Protium spruceanum, preferencialmente no interior da floresta; e Geonoma schottiana, em solos úmidos, mas não saturados.

A florestas ripárias no Brasil apresentam alta heterogeneidade ambiental e florística nas escalas de paisagem, regional (Oliveira Filho \& Ratter 1994, Metzger et al. 1997) e também local, caracterizando-se por elevada riqueza (Oliveira Filho et al. 1990), proveniente da grande variabilidade ambiental das áreas ripárias, que apresentam condições ecotonais e são ocupadas por um mosaico de tipos vegetacionais (Rodrigues \& Nave 2000). No fragmento de floresta ripária em Coqueiral, a soma de uma grande diversidade edáfica e um forte gradiente de umidade condicionaram o surgimento de diferentes hábitats e, por consequiência, de uma comunidade arbórea com elevada riqueza florística, combinando fitofisionomias facilmente distinguíveis de floresta ripária semidecidual, floresta paludosa e resquícios de cerrado, e de uma zona de transição menos evidente. A grande riqueza observada na comunidade parece estar associada ao caráter ecotonal do fragmento.

Agradecimentos - Este trabalho integra o Subprojeto "Estratégias para conservação e manejo da biodiversidade em fragmentos de florestas semidecíduas" executado pela Embrapa - Recursos Genéticos, a Universidade Federal de Lavras e Universidade de Brasília e integrante do Projeto de Conservação e Utilização Sustentável da Diversidade Biológica Brasileira, supervisionado pelo Ministério do Meio Ambiente, gerido pelo Conselho Nacional de Desenvolvimento Científico e Tecnológico e apresentado pelo governo brasileiro ao GEF/BIRD.

\section{Referências bibliográficas}

APG II. 2003. An update of the Angiosperm Phylogeny Group classification for the orders and families of flowering plants: APG II. Botanical Journal of the Linnean Society 141:399-436.

BOTREL, R.T., OLIVEIRAFILHO, A.T., RODRIGUES, L.A. \& CURI, N. 2002. Influência do solo e topografia sobre variações da composição florística e estrutura da comunidade arbóreo-arbustiva de uma floresta estacional semidecidual em Ingaí, MG. Revista Brasileira de Botânica 25:195-213.

BROWER, J.E. \& ZAR, J.H. 1984. Field and laboratory methods for general ecology. W.M.C. Brow, Dubuque.

CARVALHO, D.A., OLIVEIRAFILHO, A.T., VILELA, E.A. \& GAVILANES, M.L. 1992. Flora arbustivo-arbórea das matas ciliares do alto Rio Grande (MG). 1 - Mata de Macaia (Bom Sucesso). Revista do Instituto Florestal 4:274-282.

CARVALHO, D.A., OLIVEIRAFILHO, A.T., VILELA, E.A. \& GAVILANES, M.L. 1995. Flora arbustivo-arbórea de uma mata ciliar do Alto Rio Grande em Bom Sucesso-MG. Acta Botanica Brasilica 9:231-245.

CARVALHO, D.A., OLIVEIRA FILHO, A.T. \& VILELA, E.A. 1996. Flora arbustivo-arbórea de mata ripária do Médio Rio Grande (Conquista, Estado de Minas Gerais). Cerne 2:48-68.

CARVALHO, D.A., OLIVEIRAFILHO, A.T., VILELA, E.A. \& CURI, N. 2000. Florística e estrutura da vegetação arbórea de um fragmento de floresta ciliar do Alto São Francisco (Martinho Campos, MG). Boletim do Herbário Ezechias Paulo Heringer 6:5-22.

EMBRAPA - CNPS. 1997. Manual de métodos de análises de solo. Empresa Brasileira de Pesquisa Agropecuária, Centro Nacional de Pesquisa de Solos, Rio de Janeiro.

EMBRAPA - CNPS. 1999. Sistema brasileiro de classificação de solos. Empresa Brasileira de Pesquisa Agropecuária, Centro Nacional de Pesquisa de Solos, Rio de Janeiro.

ESPÍRITO-SANTO, F.D.B., OLIVEIRA FILHO, A.T., MACHADO, E.L.M., SOUZA, J.S., FONTES, M.A.L. \& MARQUES, J.J.G.S.M. 2002. Variáveis ambientais e a distribuição de espécies arbóreas em um remanescente de Floresta Estacional Semidecidual Montana no campus da Universidade Federal de Lavras, MG. Acta Botanica Brasilica 16:331-356. 
GIBBS, P.E., LEITÃO FILHO, H.F. \& ABBOTT, R.J. 1980. Application of the pointcentred quarter method in floristic survey of na area of gallery forest at MogiGuaçu, SP, Brasil. Revista Brasileira de Botânica 3:17-22.

IVANAUSKAS, N.M., RODRIGUES, R.R. \& NAVE, G. 1997. Fitossociologia e seletividade de espécies numa floresta de brejo em Itatinga, SP. Revista Brasileira de Botânica 20:139-153.

JOLY, C.A. 1986. Heterogeneidade ambiental e diversidade de estratégias adaptativas de espécies arbóreas de mata de galeria. In Anais do $10^{\circ}$ Simpósio da Academia de Ciências de São Paulo: perspectivas da ecologia teórica. Aciesp, São Paulo, p.19-38.

KENT, M. \& COKER, P. 1992. Vegetation description and analysis, a pratical approach. Belhaven, London.

LEITÃO FILHO, H.F. 1987. Considerações sobre a florística de florestas tropicais e sub-tropicais do Brasil. Revista do IPEF 35:41-46.

LIMA, W.P. 1989. Função hidrológica da mata ciliar. In Anais do I Simpósio sobre Mata Ciliar (L.M. Barbosa, coord.). Fundação Cargill, Campinas, p.25-42.

LORENZI, H. 1992. Árvores brasileiras: manual de identificação e cultivo de plantas arbóreas nativas do Brasil. v.2. Plantarum, Nova Odessa.

METZGER, J.P., BERNACCI, L.C. \& GOLDENBERG, R. 1997. Pattern of tree species diversity in riparian forest fragments of different widths (SE Brazil). Plant Ecology 133:132-135.

MUELLER-DOMBOIS, D. \& ELLENBERG, H. 1974. Aims and methods of vegetation ecology. Wiley and Sons, New York.

OLIVEIRA FILHO, A.T. \& FONTES, M.A.L. 2000. Patterns of floristic differentiation among Atlantic forests in southeastern Brazil, and the influence of climate. Biotropica 31:783-810.

OLIVEIRA FILHO, A.T. \& MACHADO, J.N.M. 1993. Composição florística de uma floresta semidecídua montana na Serra de São José, Tiradentes, Minas Gerais. Acta Botanica Brasilica 7:71-88.

OLIVEIRA FILHO, A.T. \& RATTER, J.A. 1994. Database: Woody flora of 106 forest areas of eastern tropical South America. Royal Botanic Garden, Edinburgh.

OLIVEIRA FILHO, A.T. \& RATTER, J.A. 2000. Padrões florísticos das matas ciliares da Região do Cerrado e a evolução das paisagens do Brasil Central durante o Quaterrnário Tardio. In Matas ciliareas: conservação e recuperação (R.R. Rodrigues \& H.F. Leitão Filho, eds.). Edusp, São Paulo, p.73-90.

OLIVEIRA FILHO, A.T., RATTER, J.A. \& SHEPHERD, G.J. 1990. Floristic composition and community structure of a Central Brazilian gallery forests. Flora 184:103-117.

OLIVEIRA FILHO, A.T., ALMEIDA, R.J., MELLO, J.M. \& GAVILANES, M.L. 1994a. Estrutura fitossociológica e variáveis ambientais em um trecho da mata ciliar do córrego dos Vilas Boas, Reserva Biológica do Poço Bonito, Lavras (MG). Revista Brasileira de Botânica 17:67-85.
OLIVEIRA FILHO, A.T., SCOLFORO, J.R. \& MELLO, J.M. 1994b. Composição florística e estrutura comunitária de um remanescente de floresta semidecídua montana em Lavras (MG). Revista Brasileira de Botânica 17:159-174.

OLIVEIRAFILHO, A.T., VILELA, E.A., CARVALHO, D.A. \& GAVILANES, M.L. 1994c. Effects of soils and topography on the distribution of tree species in a tropical riverine forest in south-eastern Brazil. Journal of Tropical Ecology 10:483-508.

OLIVEIRAFILHO, A.T., MELLO, J.M. \& SCOLFORO, J.R.S. 1997. Effects of past disturbance and edges on tree community structure and dynamics within a fragment of tropical semideciduous forest in south-eastern Brazil over a five-year period (1987-1992). Plant Ecology 131:45-66.

PASCHOAL, M.E.S. \& CAVASSAN, O. 1999. A flora arbórea da mata de brejo do Ribeirão Peliantra, Agudos - SP. Naturalia 4:171-191.

PEDRALLI, G. \& TEIXEIRA, M.C.B. 1997. Reservatórios: alternativas para proteção das comunidades vegetais na sua área de influência. Ensaios e Dissertações 5:34-41.

RODRIGUES, R.R. 2000. Uma discussão nomenclatural das formações ciliares. In Matas ciliares: conservação e recuperação (R.R. Rodrigues \& H.F. Leitão Filho, eds.). Edusp, São Paulo, p.91-107.

RODRIGUES, R.R. \& NAVE, A.G. 2000. Heterogeneidade florística das matas ciliares. In Matas ciliares: conservação e recuperação (R.R. Rodrigues \& H.F. Leitão Filho, eds.). Edusp, São Paulo, p.45-71.

RODRIGUES, R.R. \& SHEPHERD, G.J. 1993. Considerações sobre os fatores atuantes em matas ciliares e condições ecológicas dominantes na faixa ciliar do sudeste brasileiro. In Curso sobre recuperação de áreas degradadas. UFP, Curitiba.

SHEPHERD, G.J. 1994. Fitopac: manual do usuário. Unicamp, Campinas.

SOUZA, J.S., ESPÍRITO-SANTO, F.D.B., FONTES, M.A.L., OLIVEIRAFILHO, A.T. \& BOTEZELLI, L. 2003. Análise das variações florísticas e estruturais da comunidade arbórea de um fragmento de floresta semidecídua às margens do rio Capivarí, Lavras-MG. Revista Árvore 27:185-206.

TER BRAAK, C.J.F. 1987. The analysis of vegetation environment relationships bay canonical correspondence analysis. Vegetatio 69:69-77.

TONIATO, M.T.Z., LEITÃO FILHO, H.F. \& RODRIGUES, R.R. 1998. Fitossociologia de um remanescente de floresta higrófila (mata de brejo) em Campinas, SP. Revista Brasileira de Botânica 21:197-210.

TORRES, R.B., MATTHES, L.A.F., RODRIGUES, R.R. \& LEITÃO FILHO, H.F. 1992. Espécies florestais nativas para plantio em áreas de brejo. O Agronômico 44:6-13.

TORRES, R.B., MATTHES, L.A.F. \& RODRIGUES, R.R. 1994. Florística e estrutura do componente arbóreo de mata de brejo em Campinas, SP. Revista Brasileira de Botânica 17:189-194. 
VAN DEN BERG, E. \& OLIVEIRA FILHO, A.T. 1999. Spatial partitioning among tree species within an area of tropical montane gallery forest in south-eastern Brazil. Flora 194:249-246.

VAN DEN BERG, E. \& OLIVEIRA FILHO, A.T. 2000. Composição florística e estrutura fitossociológica de uma floresta ripária em Itutinga, MG, e comparação com outras áreas. Revista Brasileira de Botânica 23:231-253.
VELOSO, H.P., RANGELFILHO, A.L.R. \& LIMA, J.C.A. 1991. Classificação da vegetação brasileira adaptada a um sistema universal. IBGE, Rio de Janeiro.

VILELA, E.A. \& RAMALHO, M.A.P. 1979. Análise das temperaturas e precipitações pluviométricas de Lavras - MG. Ciência e Prática 3:71-79.

ZAR, J.H. 1996. Biostatistical analysis. Prentice-Hall, New Jersey. 